\title{
Multiple parallel ordinations: the importance of choice of ordination method and weighting of species abundance data
}

\author{
Thijs Christiaan van Son \\ and Rune Halvorsen
}

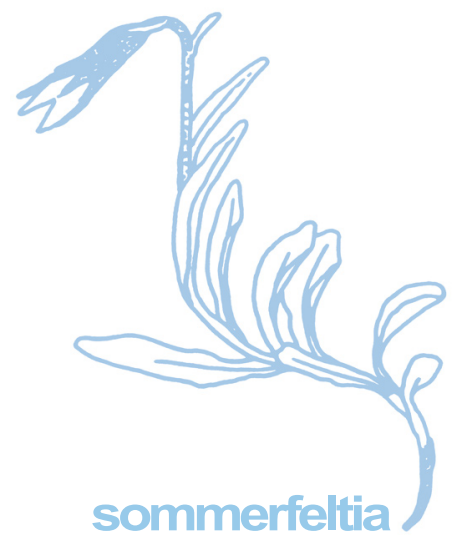

Thijs Christiaan van Son, Marine Biology Program, Department of Biosciences, University of Oslo, P.O. Box 1066 Blindern, NO-0316 Oslo, Norway

Thijs Christiaan van Son and Rune Halvorsen, Geo-Ecological Research Group (GEco), Natural History Museum, University of Oslo, P.O. Box 1172 Blindern, NO-0318 Oslo, Norway

Thijs Christiaan van Son, Marine Geology group, Geological Survey of Norway (NGU), PB 6315 Sluppen, 7491 Trondheim, Norway (present address)

thijs.vanson@runbox.com

Thijs Christiaan van Son, T. C. \& Halvorsen, R. 2014. Multiple parallel ordinations: the importance of choice of ordination method and weighting of species abundance data. - Sommerfeltia 37: 1-37. Oslo. ISBN 82-7420-051-9. ISSN 0800-6865. DOI: 10.2478/som-2014-0001.

Most species-abundance matrices subjected to ordination are analysed by applying one ordination method to one single weighting (transformation) of the raw abundance values. We argue that such an approach is sub-optimal for identification of species-environment relationships. In order to capture the full range of qualitative and quantitative components of variation unique to each species-abundance matrix, data sets covering the full range of abundance weights from presence/absence to raw abundance data should be subjected to ordination. Furthermore, two or more ordination methods should be used in parallel to enhance detection of artifacts in the results. We describe and exemplify a multiple parallel ordination (MPO) procedure, which ensures that both qualitative and quantitative properties of the data set are revealed. This procedure implies that different ordination methods are applied in parallel, each with different weightings of elements in the species-abundance matrix. Two species-abundance matrices are used to ex- 
emplify the MPO procedure, one of individual counts from a marine benthic study of mollusc and echinoderm species and one of percent cover of vascular plants, bryophytes and lichens from a study of boreal forest understory vegetation. Striking differences between point configurations obtained by different ordination methods and strong dependence of ordination results on the weights given to abundance are demonstrated. Properties of species and data sets that may explain the observed variation in ordination results are analyzed and discussed. We show that the widely held belief that changes in ordination structure with changes of weighting function are brought about only by highly abundant and frequent species is an over-simplification. We conclude that the MPO procedure - applying more than one ordination method and more than one weighting function - is likely to enhance the user's insight into the multivariate structure of species-abundance matrices resulting from ordination analyses.

Keywords: Abundance-occupancy relationship; compositional turnover, core-urban-rural-satellite species; detrended correspondence analysis; ecoclines; global nonmetric multidimensional scaling; range of abundance scale; species contribution analysis; transformation. 


\section{Contents}

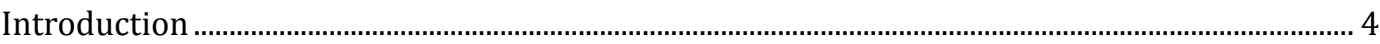

Theory: The multiple parallel ordinations (MPO) procedure ………….......................................... 5

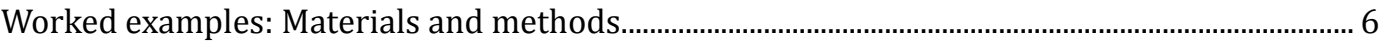

Collection of data and data-set properties: Example data set $1 \quad 6$

Collection of data and data-set properties: Example data set 2

Weighting of species-abundance data 9

$\begin{array}{ll}\text { Multivariate analyses } & 11\end{array}$

Contributions of single species to separation of sites in ordinations $\quad 11$

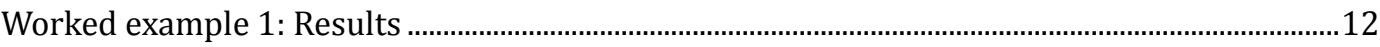

$\begin{array}{lr}\text { Abundance-occupancy relationships } & 12\end{array}$

Division of sites into clusters 12

Comparison of DCA and GNMDS ordinations 13

DCA ordinations $\quad 14$

GNMDS ordinations 14

Contributions of single species to separation of clusters in ordinations $\quad 17$

Species shifts in DCA ordination space 18

Relationships between the species contributions and site and spoecies properties $\quad 19$

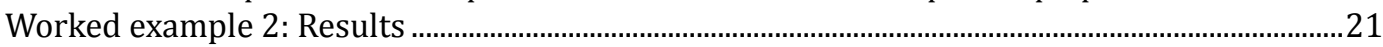

Abundance-occupancy relationships $\quad 21$

$\begin{array}{ll}\text { Identification of reference sites } & 21\end{array}$

Comparison of DCA and GNMDS ordinations 21

DCA ordinations $\quad 22$

GNMDS ordinations $\quad 24$

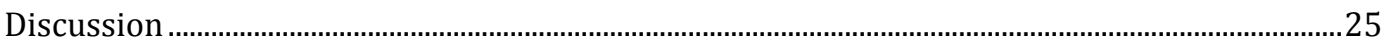

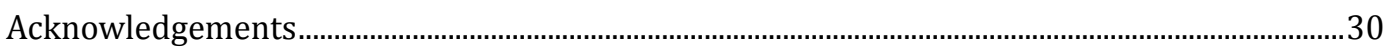

References................................................................................................................................................30

Appendix 1: Example data set 1: Complete species list .................................................................34

Appendix 2: Example data set 2: Complete species list, with affiliation to

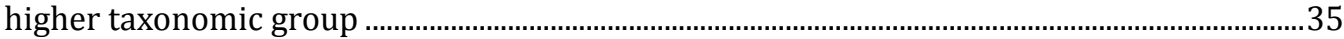




\section{INTRODUCTION}

Unconstrained ordination methods (in the following these methods will simply be referred to as "ordination methods" or just "ordination") are used in ecology to find a low-dimensional representation of the main structure in matrices of species abundances recorded for a set of sites. Species-abundance matrices inherently have a high dimensionality, typically min $(\mathrm{m}$, $n-1$ ) where $m$ is the number of species and $n$ is the number of sites. In contrast, the major, coordinated responses of species to underlying environmental complex-gradients (Whittaker 1956, R. Økland 1996), i.e., the more or less parallel change in several (single) environmental variables (Whittaker 1967), are captured on two or three ordination axes. Ordination works because most of the species co-occurring in a study area respond to the same relatively few major complex-gradients (Halvorsen 2012).

Ordination methods do not only facilitate identification of the most important gradients in species composition. They also provide a platform for interpretation of these gradients in ecological terms and, thus, for identification of major ecoclines (R. Økland 1990a) - gradients of coordinated variation in species composition and the environment (Whittaker 1967).

For more than 50 years there has been a vigorous debate over the appropriateness of different ordination methods, in search for the method that is in general best at extracting the structure in species-abundance matrices. (Minchin 1987, Wartenberg et al. 1987, Peet et al. 1988, Palmer 1993, R. Økland 1996, Legendre \& Legendre 1998, De'ath 1999, Kenkel 2006, Mahecha et al. 2007). So far, no consensus has been reached with regard to how to measure an ordination method's overall performance. As a consequence, choice of ordination method still remains a matter of personal preference. However, consensus seems to have been reached on three points: (1) that no ordination method currently available performs the best in all cases; (2) that an optimal ordination method has not yet been developed (R. Økland 1996, Kenkel 2006); and (3) that the way data are prepared before analysis (pre-ordination data manipulation; Wildi 1980) affect ordination results (van der Maarel 1982, Eilertsen et al. 1990, Rydgren 1993).

Data manipulation operations, often referred to as 'data transformations' (e.g., Noy-Meir et al. 1975, van der Maarel 1979), comprise two families of functions which are here termed standardization and weighting (van der Maarel 1979, Clymo 1980), respectively. Standardization comprises operations on species and/or site vectors, as exemplified by species-centring by subtraction of the mean abundance from each element in all species vectors [see R. Økland (1990a) for an overview of the most commonly used standardization functions]. Data weighting, on the other hand, comprises operations on each element of the species-abundance matrix. Weighting affects the range of the abundance scale, i.e., the difference between the smallest and the largest value used to represent a presence observation (R. Økland 1986a, 1990a), and, accordingly, controls the relative weight attributed to low versus high species abundances in subsequent ordination analyses (van der Maarel 1979).

The obvious way to deal with unreliability of ordination results is to apply two principally different ordination methods in parallel (to the same data) and to compare the results for congruence (R. Økland 1990a, 1996, see also Podani 1989). One example of such a parallel ordination (PO) procedure is provided by R. Økland \& Eilertsen (1993) who applied detrended correspondence analysis (DCA) and local nonmetric multidimensional scaling (LNMDS) to the same data sets. Finding congruent configurations, they concluded that the resulting structure was likely to be close to the 'true', underlying structure of the data set. Other examples of parallel ordinations are provided by, e.g., Olsgard \& Gray (1995), T. Økland (1996) and R. Økland et al. (2001) and T. Økland et al. (2003). Most published studies that make use of ordination methods present the results of one single ordination analysis, obtained by one combination of ordination 
method and weighting function (Jackson 1993, but see e.g., Wright et al. 1995, Olsgard et al. 1997). The tendency of users of ordination methods to stick to combinations of methods that have, for some reason, become standard in their field, is likely to be a result of the wide range of available ordination methods and data manipulation functions available, the multitude of possible combinations, and the lack of clear guidelines for which combination to choose.

Every species-abundance matrix is unique and contains variation that can be partitioned onto qualitative and quantitative components (Austin \& Greig-Smith 1968, R. Økland 1986b, Minchin 1987). The qualitative component is the variation brought about by species that are present in some sites and absent in others, while the quantitative component is the difference in abundance between sites in which a species is present. By choice of one weighting function, the relative weight given to qualitative vs. quantitative variation becomes fixed and only relationships for this fixed situation will be revealed by ordination. The choice of weighting function therefore impacts the final ordination result (Noy-Meir et al. 1975, van der Maarel 1979), but in ways that have been found difficult to predict from properties of the data (Eilertsen et al. 1990). This opens for the possibility that the current practice of applying one weighting function only results in an incomplete, or in some cases even a biased, picture of the gradient structure of the analysed data set. Accordingly, deeper insights into the effect of subjecting the same data set to manipulations which span the whole range from emphasis on qualitative to emphasis on quantitative properties are needed.

Another important aspect of species-abundance matrices is that they contain unique combinations with regard to the pattern of distribution and abundance of species. Some species have a wide distribution with either low ('rural' species) or high abundance ('core'), other species have a narrower distribution with either low ('satellite') or high abundance ('urban'; sensu Collins et al. 1993). The relative frequency of these four distribution-abundance patterns within a data set is likely to affect the ordination result.

In this paper, we propose a multiple parallel ordination (MPO) procedure to deal with the two sources of uncertainty in ordination analyses: (1) the uncertainty with regard to the ability of ordination methods to extract the structure in species-abundance matrices with unknown properties; and (2) the uncertainty with regard to how the structure in species-abundance matrices, extracted by ordination methods, is influenced by choice of weighting function. The main aim of this study is to describe the MPO procedure and demonstrate, by applying it to two example data sets with well-known properties, that substantial complementary information about the structure of species-abundance matrices is obtained. The examples are used to address two specific questions: (1) Can properties of species such as their affiliation with core, urban, rural, and satellite distribution patterns (Collins et al. 1993) explain the observed variation among ordinations? (2) Can the use of parallel ordinations, applied to multiple abundance ranges, provide additional insights into the structure and nature of species-abundance matrices?

\section{THEORY: THE MULTIPLE PARALLEL ORDINATIONS (MPO) PRO- CEDURE}

Multiple parallel ordinations (MPO) is the procedure by which parallel sets of ordinations are obtained by two or more ordination methods, for the full range of weighting functions from qualitative (binary, or presence/absence) data to the original (raw, unweighted) species-abundance 
data. MPO is a natural extension of the parallel ordinations (PO) procedure by which two or more ordination methods are applied in parallel to the same data set (R. Økland 1990a, 1996a), i.e., with one, specific weighting function.

Weighting of species abundances can be accomplished in several different ways and by functions of many different types (Legendre \& Legendre 1998). The weighting functions most often used in ecology are the fourth root, the square root, and the logarithmic function (e.g., Olsgard 1993, Ellingsen \& Gray 2002, Heino et al. 2003). For the MPO, we propose use of power-function weighting (van der Maarel 1979, Clymo 1980), which is a less commonly used weighting approach by which the weighted abundance of species $i$ in site $j, y_{i j^{\prime}}$ is obtained from the original abundance $x_{i j}$ by the equation

$$
y_{i j}=x_{i j}^{\frac{\log R}{\log A}}
$$

where $R$ is the range of the new abundance scale and $A$ is the range of the original abundance scale. The range of the abundance scale is defined as the ratio of the maximum value recorded for the abundance of any species, and the lowest value for recorded presence (R. Økland 1986a). By this equation, the lowest value recorded for presence is preserved from the original to the new abundance scale. The exponent $w=(\log \mathrm{R}) /(\log \mathrm{A})$ is referred to as the weighting parameter. Power-function weighting allows the full range of weightings of the abundance scale to be obtained in a step-less manner by changing one single parameter, $w$ (R. Økland 1986a) - from presence/absence data ( $w=0$; only qualitative variation expressed) to whichever high weighting of abundance desired by the user $(w \rightarrow+\infty)$. However, the strongest realistic emphasis to quantitative variation corresponds to $w=1$, i.e., that raw abundance data are used. Variation in the relative emphasis on low vs. high abundance values with changes of $w$ is illustrated in Fig. 1.

\section{WORKED EXAMPLES: MATERIAL AND METHODS}

We use two data sets to illustrate the MPO procedure: Example data set 1 of individual counts from a marine benthic study of mollusc and echinoderm species, and example data set 2 of percent cover of vascular plants, bryophytes and lichens from a study of boreal forest understory vegetation. In addition, the simpler Example data set 1 is subjected to a detailed analysis of the contributions of different species to ordination results.

\section{COLLECTION OF DATA AND DATA-SET PROPERTIES: EXAMPLE DATA SET 1}

The benthic macrofauna was sampled within an area of $1.05 \mathrm{~km}^{2}$ in the Oslofjord, SE Norway (UTM 32N bounding coordinates; NW corner: 6631500, 584725; SE corner: 6630500, 585775). Samples were collected from a research vessel during March and April 2009. At each site, four samples were collected using a $0.1 \mathrm{~m}^{2}$ van Veen grab. On the vessel, each sample was sieved on $5 \mathrm{~mm}$ and $1 \mathrm{~mm}$ sieves. All molluscs and echinoderms were kept in $70 \%$ ethanol until identified in the laboratory to the species level or to the lowest taxon possible. The primary data matrix 


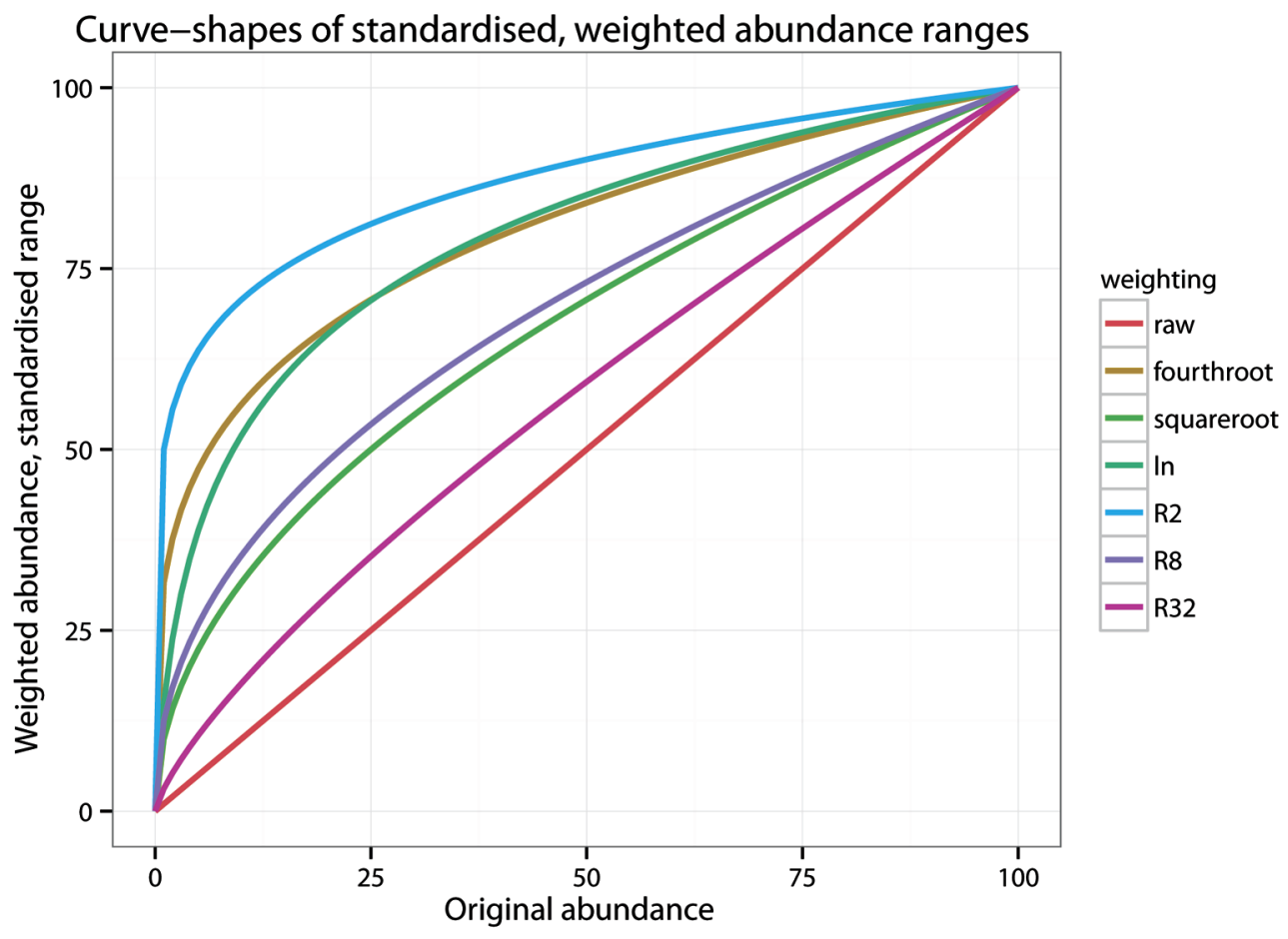

Fig. 1. Weighted abundance as a function of original abundance, for different weighting functions. Weighted abundance is expressed on a standard scale with maximum abundance set equal to 100 . The curves illustrate how strongly differences between large abundance values are de-emphasized by different weighting functions. In addition to power-function weighting to ranges of the abundance scale of 2 (R2), 8 (R8) and 32 (R32), commonly used weighting functions (use of raw values and weighting by ln-, square root- and fourth-root functions) are shown. Weighting functions R2, R8 and R32 correspond to weighting parameters $w$ of 0.150 , 0.452 , and 0.753 , respectively, while the corresponding $w$ values for square-root and fourth-root functions are $w=0.250$ and $w=0.500$, respectively.

consisted of abundances of each species in each sample, recorded as numbers of identified individuals (individual counts). For this study, the four samples per site were pooled. A total of 46 mollusc and echinoderm species were recorded, the species richness per site ranged between 6 and 23 (Fig. 2, top), the median species richness per site was 13.5. A total of 4941 individuals were collected, the total abundance per site varied between 35 and 452 (Fig. 2, middle) with a median abundance per site of 159 . The frequency of occurrence, i.e. the number of sites in which each species was found (Halvorsen 2012) varied between 1 and 28 (Fig. 2, bottom) with a median frequency of 4.5. The fill (i.e., the proportion of non-zero entries) of the speciesabundance matrix was 0.301 . The sum of squares for the qualitative and the raw data sets were, 372.5 and 778373 , respectively. Thus, the relative contribution of qualitative information to the total variation in the data set was $0.048 \%$.

Sampling sites were allocated according to geomorphological features using a Guided Stratified Sampling Strategy (GSSS). The GSSS is based on a modified algorithm by Lundblad et al. 2006 that classifies the seabed into geomorphological features by using a fine-scaled and a 

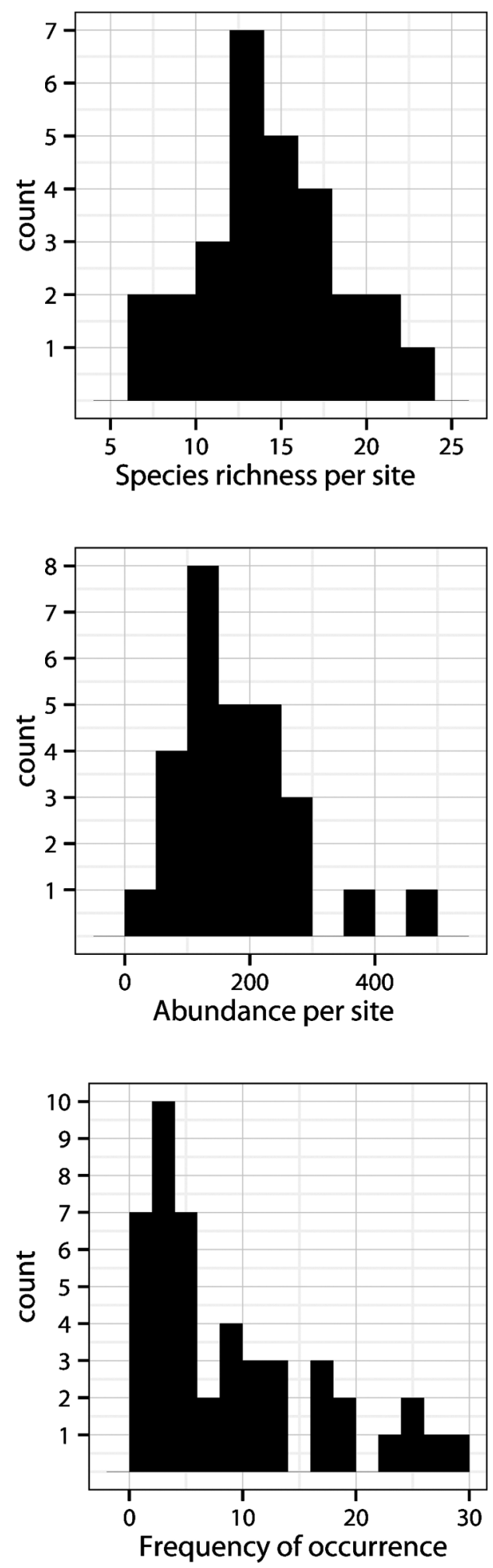

Fig. 2. Example data set 1: histograms showing some of properties of the species-abundance matrix. Top: distribution of species richness per site; middle: distribution of abundance per site; bottom: distribution of frequency of occurrence of species. 
broad-scaled bathymetric position index (BPI) and slope as input variables. In addition, mean depth was used to classify certain features into their shallow and deep representations. In this study, six geomorphological features, depression, crest, shallow slope, shallow flat, deep slope, and deep flat were identified and mapped. A total of 28 sample sites were positioned by restricted random placement within each geomorphological feature, using the GSSS. This procedure ensured that all six geomorphological features were about equally well represented (3- 6 sites per geomorphological feature) among the selected sites. Geomorphological features covering larger proportions of the total study area were sampled more than features covering less of the total area.

\section{COLLECTION OF DATA AND DATA-SET PROPERTIES: EXAMPLE DATA SET 2}

Understory vegetation (vascular plants $<2 \mathrm{~m}$ high, bryophytes and macrolichens) were sampled in 61 sites within an area of ca. $2 \mathrm{~km}^{2}$ in the Solhomfjell area, S Norway (UTM 32V bounding coordinates; SW corner: 65351, 4889; NE corner: 65357, 4915). The $1-\mathrm{m}^{2}$ sites were placed semi-systematically along eight transects, subjectively selected to cover the variation in boreal forest vegetation in the area [see R. Økland \& Eilertsen (1993) for details]. Only 61 (out of a total of 200) sites in forest dominated by Norway spruce (Picea abies L.) was used for this study [sites in the series 1-100 of R. Økland \& Eilertsen (1993) that belonged to Subset A Spruce forest]. During field work in 1993, the percent cover of all species in all sites was visually estimated to the nearest 1\%. A total of 128 species ( 55 vascular plants, 70 bryophytes and 3 lichens) were recorded. Species richness per site varied between 5 and 52 (Fig. 3, top), the median species richness per site was 23 . The total abundance (grand sum of cover values) was 6016 , varying among sites from 22 to 197 (Fig. 3, middle) with a median total abundance per site of 106 . The frequency of occurrence of the species varied between 1 and 60 (Fig. 3, bottom) with a median frequency of 5.5. The fill (i.e., the proportion of non-zero entries) of the species-abundance matrix was 0.187 . The sum of squares for the qualitative and the raw data sets were, 756.3 and 81829 , respectively. Thus, the relative contribution of qualitative information to the total variation in the data set was $0.924 \%$.

\section{WEIGHTING OF SPECIES-ABUNDANCE DATA}

From the raw species-abundance matrices we derived 12 and 9 data sets for Example data sets 1 and 2, respectively. These data sets differed with respect to weighting function: (1) qual - use of qualitative (binary, or presence-absence) data (e.g., Wright et al. 1995); (2) $\log$-weighting by the natural log function (e.g., Heino et al. 2003); (3) sqr - weighting by the square-root function (e.g., Ellingsen \& Gray 2002); (4) raw - use of unweighted abundance data, which ranged from 1 to maxima of 315 and 75 for Example data sets 1 and 2, respectively; and (5-9(11)) powerfunction weighting, using five or seven different values of the weighting parameter $w$ for each of Example data sets 1 and 2, respectively (denoted $w_{1}$ and $w_{2}$ ), to obtain logarithmic series of transformed data sets: R2 (range of the abundance scale $=2$, corresponding to $w_{1}=0.120$ and $\left.w_{2}=0.161\right), \mathrm{R} 4\left(w_{1}=0.241\right.$ and $\left.w_{2}=0.321\right), \mathrm{R} 8\left(w_{1}=0.361\right.$ and $\left.w_{2}=0.482\right), \mathrm{R} 16\left(w_{1}=0.482\right.$ and $\left.w_{2}=0.642\right), \mathrm{R} 32\left(w_{1}=0.602\right.$ and $\left.w_{2}=0,803\right), \mathrm{R} 64\left(w_{1}=0.723\right)$, and R128 $\left(w_{1}=0.843\right)$. For Example data set 1 we included as a twelfth weighting function (12) fort - weighting by the 

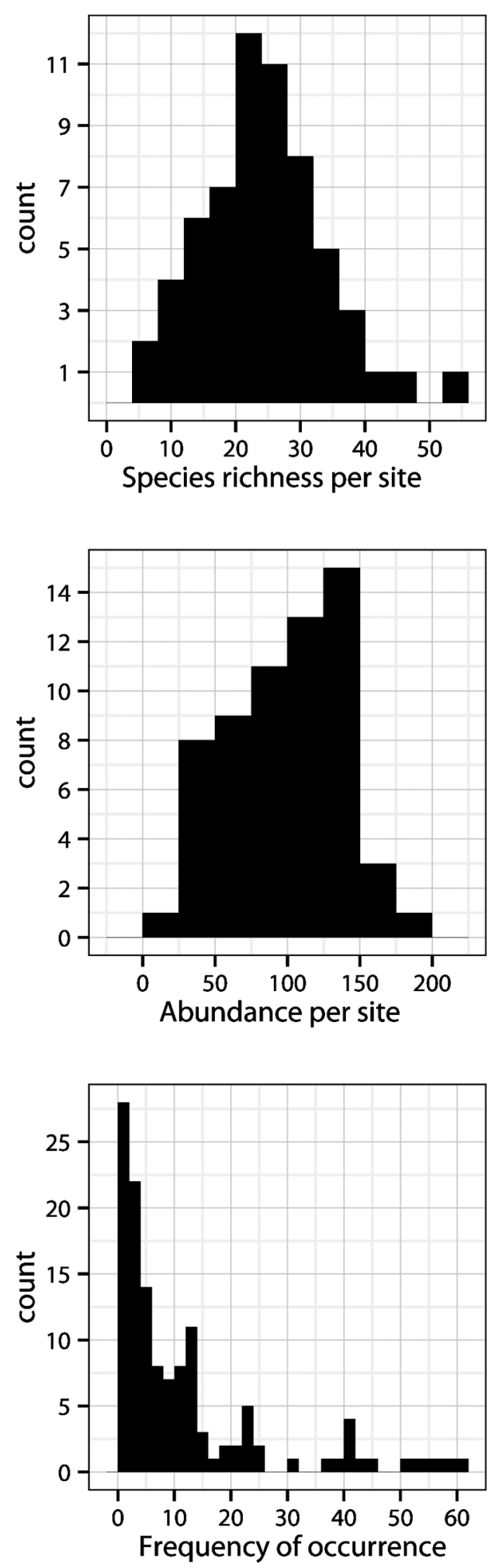

Fig. 3. Example data set 2: histograms showing some of properties of the species-abundance matrix. Top: distribution of species richness per site; middle: distribution of abundance per site; bottom: distribution of frequency of occurrence of species. 
fourth-root function (Olsgard 1993) - which is often used in marine ecological studies.

\section{MULTIVARIATE ANALYSES}

All 12 and 9 data sets for Examples 1 and 2, respectively, were subjected to multiple parallel ordinations (MPO) by DCA (Hill 1979, Hill \& Gauch 1980) and GNMDS (Minchin 1987). R, version 2.15 (R Development Core Team 2012) was used for all statistical analyses and the vegan package version 2.0-4 (Oksanen et al. 2012) for R was used for all multivariate analyses. DCA ordination was performed by the decorana function with default arguments: detrending by segments, non-linear rescaling of axes in S.D. (standard deviation) units, and no down-weighting of rare species. GNMDS ordinations were obtained by the functions initMDS, isoMDS, and postMDS. We used a matrix of Bray-Curtis dissimilarity index values as input to the GNMDS. This coefficient was used since it has been shown to optimize detection of known site assemblages and identification of environmentally interpretable gradients in species composition (Faith et al. 1987, Cao \& Epifanio 2010), and because it is nearly linearly related to distance along underlying ecological complex-gradients for data sets with small or moderate compositional variation (R. Økland 1986b). For each data set, GNMDS results were obtained from 100 random starting configurations, with maximum number of iterations $=500$ and convergence criterion $=10^{-7}$. The postMDS function was applied to rotate the best result to maximum variation explained on axes of lowest possible order (varimax rotation by PCA), followed by rescaling of the axes in H.C. (half-change) units (Gauch 1973a). Procrustes analysis was used to compare pairs of DCA and GNMDS ordinations obtained for data based on the same range of the abundance scale. Procrustes analysis implies that one ordination result is rotated to maximum overall similarity of configuration with another result by origin translation, mirror imaging, and linear rescaling of axes (Oksanen et al. 2012). The degree of overall similarity between pairs of ordinations is expressed as the Procrustes correlation coefficient $r$, which is a correlation-like statistic derived from symmetric Procrustes sum of squares (ss): $r=\operatorname{sqrt}(1-\mathrm{ss})$. GMNDS ordination requires selection of the number of dimensions (ordination axes) by the user prior to analysis. We determined the dimensionality of GNMDS ordinations separately for Example data sets 1 and 2 by an iterative procedure as follows: (1) We obtained two-dimensional GNMDS ordinations for data sets corresponding to different weighting functions. (2) Higher-dimensional GNMDS ordinations, were obtained until the demand that all axes in at least one GNMDS ordination (i.e., for at least one weighting function) had Kendall's rank correlation coefficients $\tau>0.3$ with corresponding DCA axes was no longer satisfied. (3) We used GNMDS ordinations with the number of dimensions at which the criterion above was satisfied: two for Example data set 1 and three for Example data set 2 .

\section{CONTRIBUTIONS OF SINGLE SPECIES TO SEPARATION OF SITES IN ORDINATIONS}

For Example data set 1, we conducted a species contribution analysis (SCA) to analyse the relative contribution of different species to the formation of three clusters of sites that appeared in some ordinations (see Results). These clusters were termed 'the black cluster', 'the blue cluster', and 'the red cluster', respectively. We performed the SCA by a four-step procedure: (1) For each cluster, the average abundance for all sites belonging to a specific cluster was calculated for each 
species for three weighting functions: qual, R16, and raw. (2) For each combination of species, pair of clusters (i.e., black-blue, black-red, and blue-red), and weighting function, the absolute value of the difference in average abundance was calculated. (3) For each combination of pair of clusters and weighting function, an estimate of the total compositional difference was obtained by summing absolute-value abundance differences over all species. (4) For each species, and for each combination of cluster-pairs and weighting function, the proportional contribution of the species to the separation of two clusters was obtained by dividing the absolute-value abundance difference for the species in question by the sum of these differences over all species. The SCA differs from the SIMPER analysis (Clarke 1993) by operating on absolute values of average abundance values rather than on absolute values of pairwise abundance differences between site pairs.

Further comparisons of the three clusters were made by calculating Bray-Curtis dissimilarities between the three blue sites, the three red sites, and three randomly selected sites in the black cluster (selected using the sample function without replacement). The Bray-Curtis dissimilarity matrix returned nine combinations ( 3 sites $\times 3$ sites) for each comparison of cluster-pairs. From each set of these nine Bray-Curtis values we used the median, minimum and maximum values to represent Bray-Curtis dissimilarities between pairs of clusters.

\title{
WORKED EXAMPLE 1: RESULTS
}

\author{
ABUNDANCE-OCCUPANCY RELATIONSHIPS
}

Example data set 1 was characterised by a strong, positive abundance-occupancy relationship (AOR), as shown by Kendall's $\tau=0.6471\left(p<10^{-8}, n=46\right)$ between the proportion of sites occupied and average abundance (Fig. 4). The combination of high occupancy and low average abundance did not occur, and only one species, Lepeta caeca, combined low occupancy with relatively high average abundance (Fig. 4).

The species segregated into three relatively distinct groups according to their average abundance in the data set (Fig. 4): (1) Ennucula tenuis, which was the only species with an average abundance above 100; (2) a group of about eight species with average abundances between 5 and 20; and (3) a group formed by the remaining species, all of which had average abundance below 5 .

\section{DIVISION OF SITES INTO CLUSTERS}

The 28 sites could be divided into three clusters by their behaviour in the ordinations. The clusters were given different colours and shapes to better distinguish them in the ordination diagrams: (1) 'the black cluster' (indicated by black circles in Figs. 4-6, 8 and 9), which contained 22 sites with average of total abundance (summed over all species) per site $=196.3(\mathrm{sd}=89.5)$; (2) 'the blue cluster' (blue triangles) which contained 3 sites with average total abundance $=110.3(\mathrm{sd}=24.5)$; and (3) 'the red cluster' (red squares), which contained 3 sites with average total abundance $=97.0(\mathrm{sd}=53.9)$. 


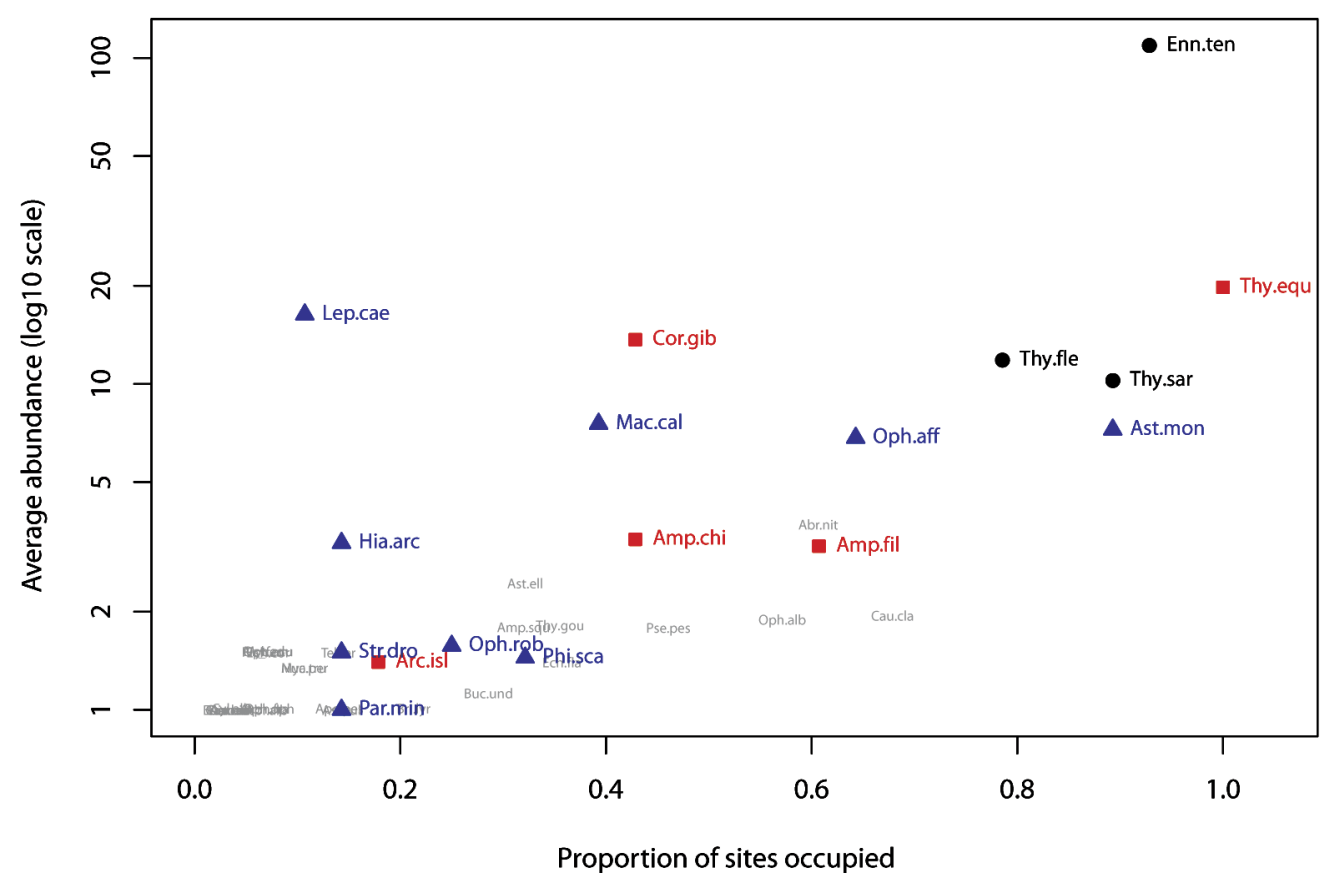

Fig. 4. Example data set 1: abundance-occupancy relationships (AOR). The relationship between occupancy (proportion of sites occupied by a species) and the species' abundance (average number of individuals recorded at sites where the species is present). Species most strongly contributing to the separation of site clusters in ordinations are coded by colour and symbol shape (black, $\bullet$; blue, $\boldsymbol{\Delta}$; and red, $\mathbf{a}$ ) for the cluster in which the species had its highest mean abundance. Names of remaining species are in grey.

\section{COMPARISON OF DCA AND GNMDS ORDINATIONS}

The high Procrustes correlation coefficients $r$ (between 0.70 and 0.95 ) observed between DCA and GNMDS ordinations obtained for the same weighting function indicated a generally high concordance between parallel ordinations (Table 1). The pair-wise similarity between corresponding first axes of DCA and GNMDS ordinations of the same data set, expressed as Kendall's $\tau$, varied from $\tau=0.78$ to $\tau=0.90$ (Table 1 ). Best concordance was observed for intermediate ranges of the abundance scale, with a distinct maximum for weighting by the natural log function $(R=5.8)$. The corresponding correlations between the second axes were considerably lower (Kendall's $\tau=0.18-0.48$; Table 1 ). The highest correlation coefficient was observed for weighting by the fourth-root function $(\mathrm{R}=4.2)$, but no clear pattern of variation in $\tau$ with $R$ was observed for the second axes. 
Table 1. Example data set 1: comparison of DCA and GNMDS results. Range refers to the range of the abundance scale (i.e., the ratio between maximum and minimum values for presence observations) for the respective weighting functions. $r=$ the Procrustes correlation coefficient, $\tau 1$ and $\tau 2=$ Kendall's rank correlation coefficients between the first and second axes, respectively, of DCA and GNMDS obtained from data sets with given weighting of abundance.

\begin{tabular}{|c|c|c|c|c|}
\hline Weight & Range & $\mathbf{r}$ & $\tau 1$ & $\tau 2$ \\
\hline qual & 1.0 & 0.70 & 0.78 & 0.31 \\
\hline $\mathrm{R} 2$ & 2.0 & 0.77 & 0.80 & 0.37 \\
\hline $\mathrm{R} 4$ & 4.0 & 0.84 & 0.81 & 0.47 \\
\hline fort & 4.2 & 0.84 & 0.83 & 0.48 \\
\hline $\log$ & 5.8 & 0.89 & 0.90 & 0.30 \\
\hline R8 & 8.0 & 0.85 & 0.86 & 0.25 \\
\hline R16 & 16.0 & 0.91 & 0.86 & 0.34 \\
\hline sqr & 17.7 & 0.92 & 0.85 & 0.32 \\
\hline R32 & 32.0 & 0.93 & 0.80 & 0.26 \\
\hline R64 & 64.0 & 0.94 & 0.79 & 0.18 \\
\hline R128 & 128.0 & 0.95 & 0.79 & 0.43 \\
\hline raw & 315.0 & 0.92 & 0.79 & 0.24 \\
\hline
\end{tabular}

\section{DCA ORDINATIONS}

The DCA results were affected in four main ways by change in the weight given to abundance (Fig. 5). With increasing range of the abundance scale, (1) sites in the black cluster made up an increasingly tight cluster (contraction of the range spanned along both ordination axes); (2) the red and blue clusters retained their dimensions but became increasingly strongly separated from the black cluster (for $R>8$ by a clear gap, a disjunction; sites in different clusters separated by at least 0.5 S.D. units); (3) the red and blue clusters were increasingly separated from each other along DCA axis 2; and (4) an outlying site in ordinations with $R \leq 8$, indicated by a black, open circle in Fig. 5, moved towards lower scores along both DCA axes and, from $R=16$, became part of the black cluster.

\section{GNMDS ORDINATIONS}

Changing the range of the abundance scale by weighting impacted GNMDS ordinations partly in similar, partly in different ways than DCA (Fig. 6). DCA patterns (1) and (2) recurred in GNMDS to some degree while DCA patterns (3) and (4) were replaced by GNMDS-specific patterns (3)-(6). The main GNMDS patterns were as follows: With increasing range of the abundance scale, (1) tightening of the black cluster took place along GNMDS axis 1, but not along GNMDS axis 2; (2) the red and blue clusters became increasingly strongly separated from the black cluster (but not from each other); (3) the spread of sites within the red and blue clusters along GNMDS axis 

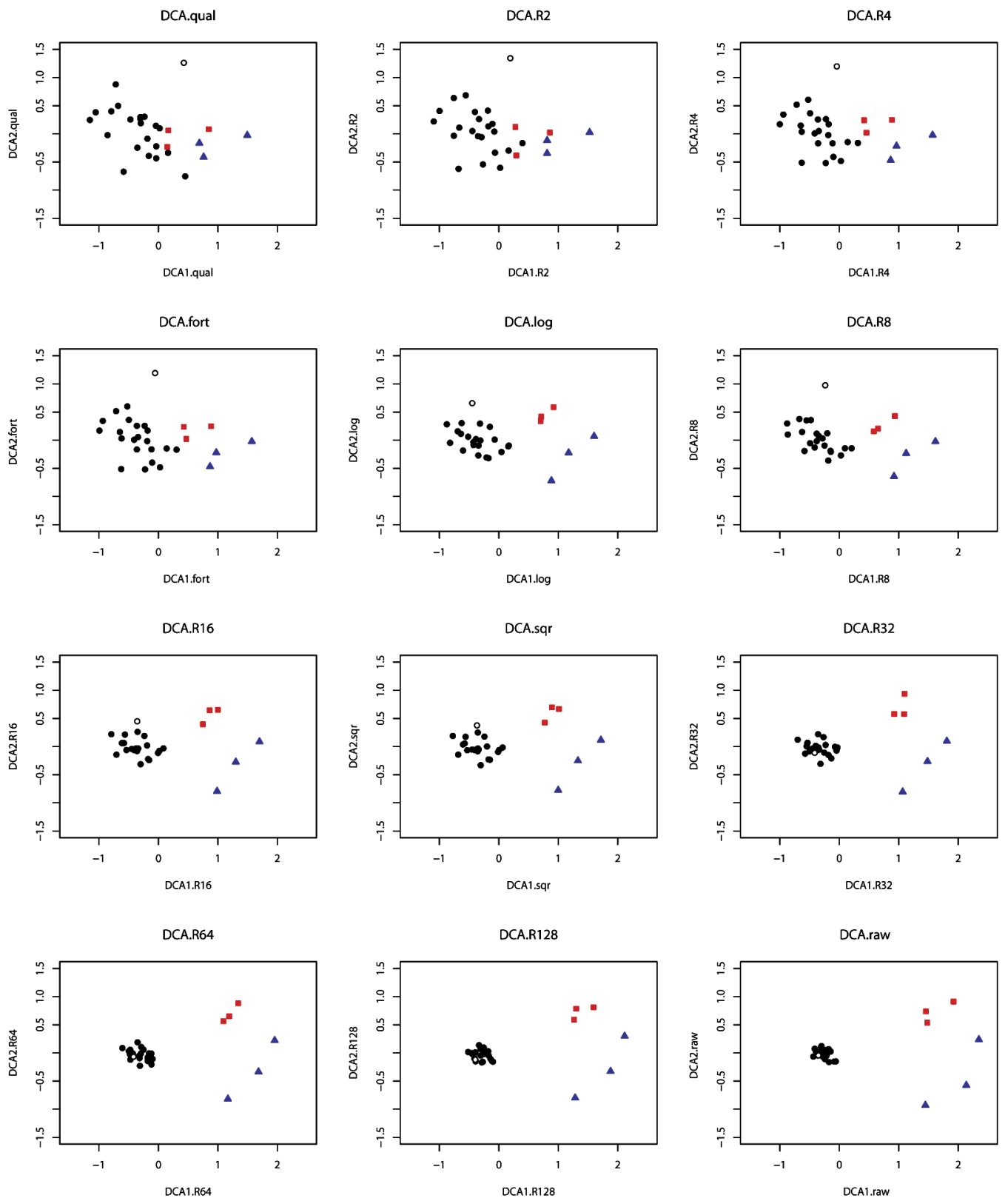

Fig. 5. Example data set 1: DCA results for different ranges of the abundance scale (weighting functions). Symbols with different colours and shapes (black, $\bullet$; blue, $\boldsymbol{\Delta}$; and red, $\mathbf{\square}$ ) are used for the three disjunct clusters of sites formed when the range of the abundance scale increases. The black, open circle shows an outlying site in the black cluster. Axes are scaled in S.D. (standard deviation) units. 

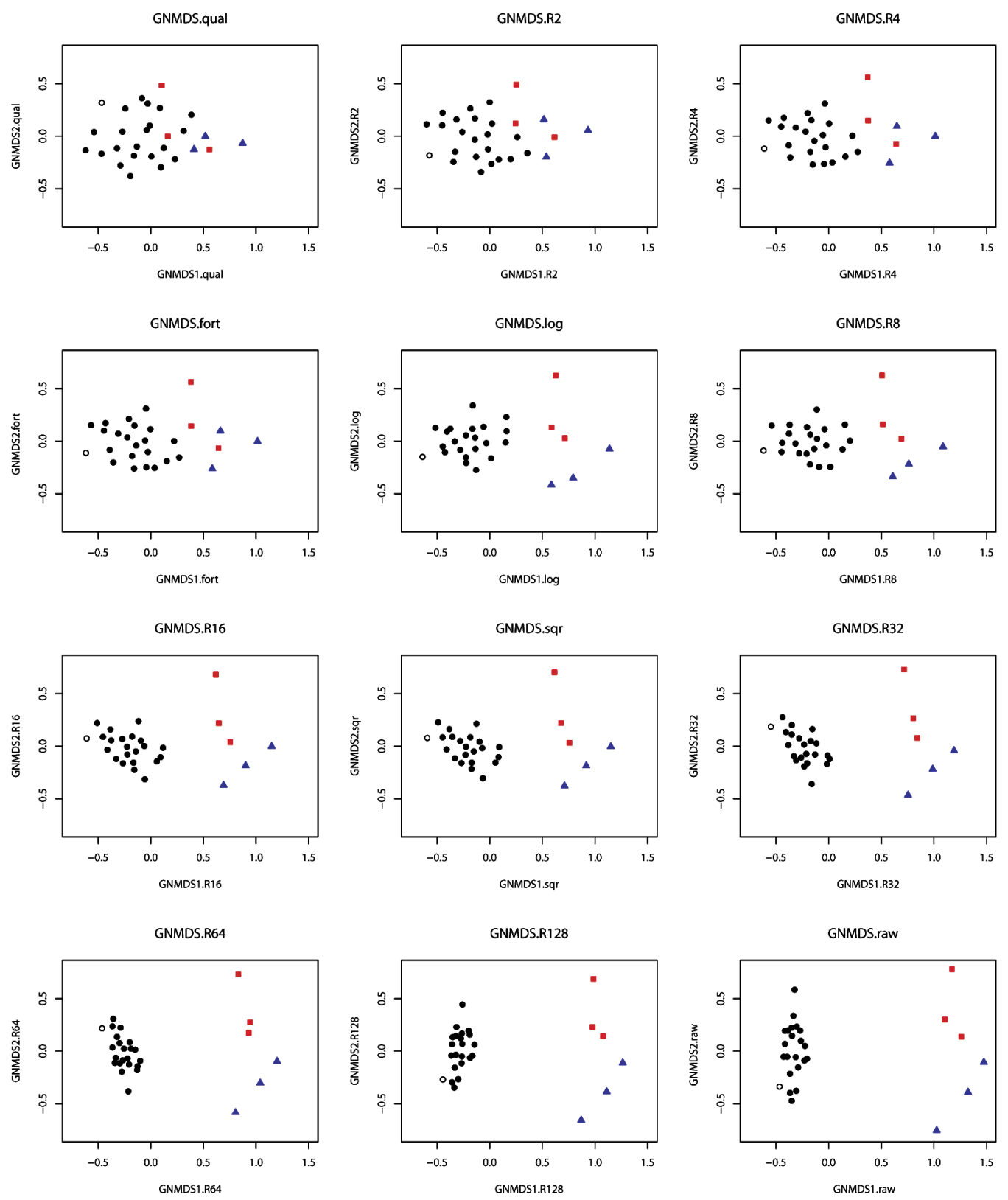

Fig. 6. Example data set 1: GNMDS results for different ranges of the abundance scale (weighting functions). Symbols with different colours and shape (black, $\bullet$; blue, $\boldsymbol{\Delta}$; and red, $\mathbf{\square}$ ) are used for the three disjunct clusters of sites formed when the range of the abundance scale increases. The black, open circle shows an outlying site in the black cluster. Axes are scaled in H.C. (half change) units. 
Table 2. Example data set 1 : average raw abundance for the 17 most strongly contributing species according to the species contribution analysis. Each species' average abundance is given for each of the Black $(\bullet)$, Blue $(\boldsymbol{\Delta})$, and Red ( $\boldsymbol{\bullet}$ ) clusters, respectively. Names are given in bold for species that contribute more than $10 \%$ to differences between at least one pair of clusters. Full species names are given in Appendix 1.

\begin{tabular}{|c|c|c|c|}
\hline \multirow[b]{2}{*}{ Species } & \multicolumn{3}{|c|}{ Average (raw) abundance } \\
\hline & Black (•) & Blue (A) & Red (a) \\
\hline Arc.isl & 0.1 & 0.7 & 1.0 \\
\hline Ast.mon & 6.0 & 11.7 & 4.3 \\
\hline Cor.gib & 0.5 & 19.3 & 31.3 \\
\hline Enn.ten & 128.3 & 4.0 & 1.0 \\
\hline Hia.arc & 0.0 & 3.7 & 0.7 \\
\hline Lep.cae & 0.0 & 16.3 & 0.0 \\
\hline Mac.cal & 3.1 & 4.7 & 0.0 \\
\hline Par.min & 0.0 & 1.0 & 0.0 \\
\hline Phi.sca & 0.3 & 1.7 & 0.3 \\
\hline Thy.equ & 21.6 & 3.3 & 22.7 \\
\hline Thy.fle & 11.5 & 1.7 & 1.0 \\
\hline Thy.sar & 11.0 & 0.7 & 3.7 \\
\hline Amp.chi & 0.5 & 3.3 & 6.7 \\
\hline Amp.fil & 1.3 & 2.0 & 6.7 \\
\hline Oph.aff & 2.1 & 20.0 & 5.3 \\
\hline Oph.rob & 0.1 & 2.0 & 0.7 \\
\hline Str.dro & 0.0 & 1.7 & 0.0 \\
\hline
\end{tabular}

2 increased; (4) the site acting as an outlier in DCA (indicated by the black, open circle in Fig. 6) remained within the black cluster and occupied a stable position at the low-score end of GNMDS axis 1 while its position along GNMDS2 varied; (5) the spread of sites in the red cluster along GNMDS axis 1 was reduced, and (6) the gradient lengths of GNMDS axes 1 and 2 (i.e., the range of sites scores along the respective axes) increased from 1.5 to 2.0 H.C. units and from 0.9 to 1.2 H.C. units, respectively.

\section{CONTRIBUTIONS OF SINGLE SPECIES TO SEPARATION OF CLUSTERS IN ORDINATIONS}

A total of 17 species (37\% of the total number of species) contributed more than $5 \%$ to the separation of at least one pair of clusters while five of these species contributed more than $10 \%$. The average abundance varied much, both between species and between clusters: E. tenuis, Thyasira flexuosa, and T. sarsi had abundance peaks in the black cluster; L. caeca, Ophiura affinis, and Astarte montagui peaked in the blue cluster, while Corbula gibba and T. equalis peaked in the red cluster (Table 2). The two last-mentioned species also had high abundances in other clusters. Not surprisingly, the evenness of proportional contributions decreased strongly when 
Table 3. Results of species contribution analysis (SCA). The SCA is conducted for all three pairs of clusters for the three weighting functions qual, R16 and raw. The average contribution by a species is $2.17 \%$ (100\%/46 species). Contributions above $5 \%$ are shown in bold and contributions above $10 \%$ in bold and italics. Names are given in bold for species that contribute more than $10 \%$ to differences between at least one pair of clusters. Full species names are given in Appendix 1.

\begin{tabular}{|c|c|c|c|c|c|c|c|c|c|}
\hline \multirow[b]{2}{*}{ Species } & \multicolumn{3}{|c|}{ Black vs Blue (• vs $\Delta$ ) } & \multicolumn{3}{|c|}{ Black vs Red (• vs घ) } & \multicolumn{3}{|c|}{ Blue vs Red ( $\Delta$ vs $\square)$} \\
\hline & qual & R16 & raw & qual & R16 & raw & qual & R16 & raw \\
\hline Arc.isl & 0.02 & 0.01 & 0.00 & 0.06 & 0.02 & 0.00 & 0.03 & 0.01 & 0.00 \\
\hline Ast.mon & 0.01 & 0.02 & 0.02 & 0.01 & 0.00 & 0.01 & 0.00 & 0.04 & 0.07 \\
\hline Cor.gib & 0.05 & 0.08 & 0.08 & 0.07 & 0.15 & 0.15 & 0.00 & 0.04 & 0.11 \\
\hline Enn.ten & 0.02 & 0.20 & 0.50 & 0.03 & 0.30 & 0.61 & 0.00 & 0.03 & 0.03 \\
\hline Hia.arc & 0.06 & 0.04 & 0.01 & 0.03 & 0.01 & 0.00 & 0.06 & 0.05 & 0.03 \\
\hline Lep.cae & 0.06 & 0.09 & 0.07 & 0.00 & 0.00 & 0.00 & 0.09 & 0.14 & 0.15 \\
\hline Mac.cal & 0.02 & 0.01 & 0.01 & 0.04 & 0.03 & 0.02 & 0.06 & 0.06 & 0.04 \\
\hline Par.min & 0.06 & 0.02 & 0.00 & 0.00 & 0.00 & 0.00 & 0.09 & 0.04 & 0.01 \\
\hline Phi.sca & 0.05 & 0.02 & 0.01 & 0.01 & 0.00 & 0.00 & 0.06 & 0.03 & 0.01 \\
\hline Thy.equ & 0.00 & 0.05 & 0.07 & 0.00 & 0.00 & 0.00 & 0.00 & 0.09 & 0.18 \\
\hline Thy.fle & 0.03 & 0.05 & 0.04 & 0.02 & 0.07 & 0.05 & 0.03 & 0.00 & 0.01 \\
\hline Thy.sar & 0.04 & 0.06 & 0.04 & 0.03 & 0.05 & 0.04 & 0.03 & 0.04 & 0.03 \\
\hline Amp.chi & 0.05 & 0.03 & 0.01 & 0.07 & 0.07 & 0.03 & 0.00 & 0.03 & 0.03 \\
\hline Amp.fil & 0.03 & 0.01 & 0.00 & 0.05 & 0.06 & 0.03 & 0.00 & 0.04 & 0.04 \\
\hline Oph.aff & 0.03 & 0.07 & 0.07 & 0.05 & 0.03 & 0.02 & 0.00 & 0.08 & 0.14 \\
\hline Oph.rob & 0.03 & 0.02 & 0.01 & 0.05 & 0.02 & 0.00 & 0.00 & 0.02 & 0.01 \\
\hline Str.dro & 0.06 & 0.03 & 0.01 & 0.00 & 0.00 & 0.00 & 0.09 & 0.05 & 0.02 \\
\hline
\end{tabular}

increased weight was given to abundance, implying that fewer species contributed more strongly to separation of clusters (Table 3). The quantitatively most important species in this data set, E. tenuis, increased its contribution to differences between the black cluster and each of the red and blue clusters from an average of 0.03 for qualitative data, via 0.25 for $R=16$, to 0.56 for raw data. The contribution of $C$. gibba to separation between the black and red clusters increased from 0.07 to 0.15 with increasing $R$ value. For all of the species T. equalis, L. caeca, O. affinis, and C. gibba, which contributed particularly strongly to the separation of the blue and red clusters, increasing contributions to cluster separation were observed with increasing $R$ value.

Bray-Curtis dissimilarities increased with increasing $R$ in all cluster-wise comparisons (Fig. 7). However, with increasing $R$ the dissimilarity between the blue and red clusters increased less strongly than the dissimilarity between each of these with the black cluster.

\section{SPECIES SHIFTS IN DCA ORDINATION SPACE}

Of the 17 species that contributed most strongly to differences between cluster pairs in the 


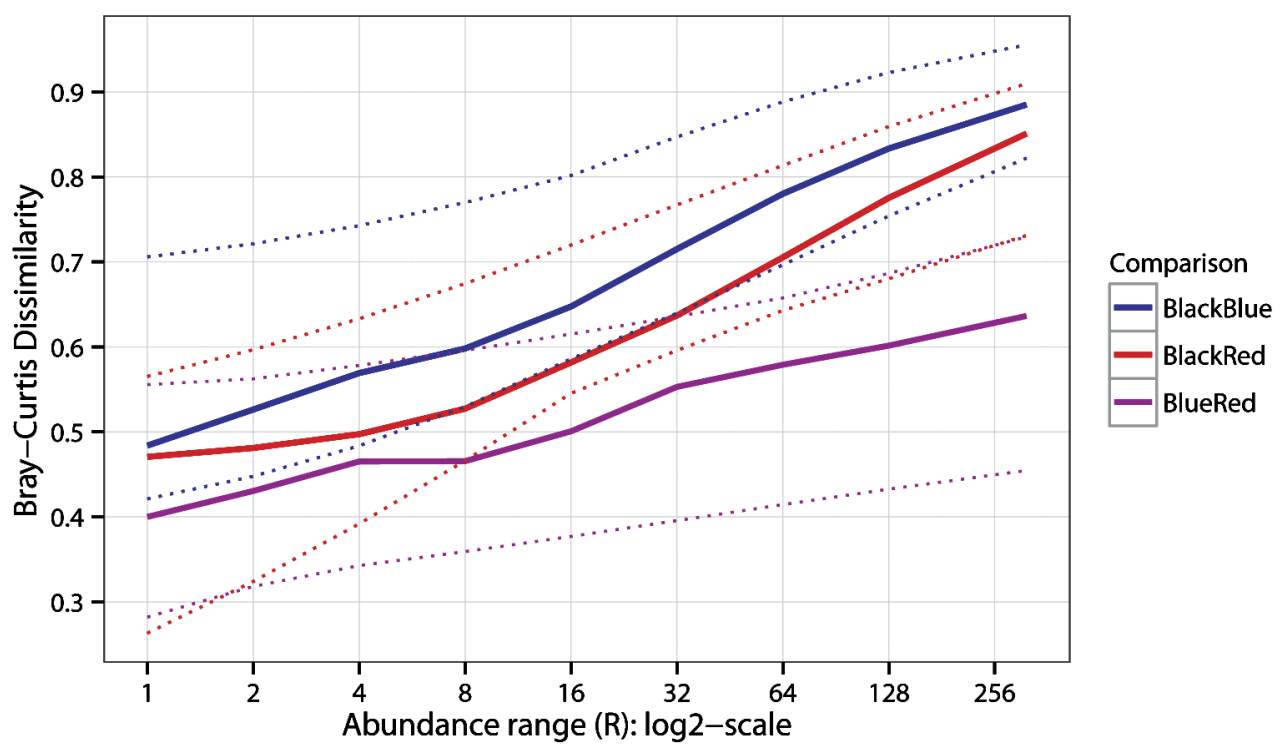

Fig. 7. Example data set 1: changes in Bray-Curtis dissimilarities for comparisons of clusterpairs of the black $(\bullet)$, blue $(\boldsymbol{\Delta})$, and red ( $\mathbf{\square})$ clusters as a function of the range of the abundance scale $(R)$. Each of the three clusters are represented by three sites each. For the black cluster the three sites $(3,12$, and 19$)$ were randomly selected. The thick lines represent median dissimilarities while the dotted lines represent the minimum and maximum dissimilarities for each pair of clusters.

ordinations, three had abundance peaks in the black cluster, five in the red cluster, and nine in the blue cluster. For these species, DCA species scores (i.e., estimates for species optima) were unstable for most species when abundance was given low weight, while patterns stabilized with increasing $R$ (Fig. 8). Fluctuations were particularly strong along DCA 2 . There was a clear trend of shifts of species optima towards higher DCA-axis 1 scores with increasing weight given to abundance. Fig. 8 clearly shows how species migrate in ordination space with increasing abundance range and how they contribute to define the clusters with which they are most strongly affiliated.

RELATIONSHIP BETWEEN THE SPECIES CONTRIBUTIONS AND SITE AND SPECIES PROPERTIES

The species that contributed most to the observed structure (black-, blue-, and red-coloured labels and their corresponding symbols show which cluster each species contributed most strongly to) spanned the whole range of variation both in mean abundance and proportion of sites occupied (Fig. 4). The three species with highest abundance in the black cluster were all present in $80 \%$ or more of the sites while species with abundance peaks in the blue and red cluster spanned the whole spectrum of variation in occupancy and abundance. 


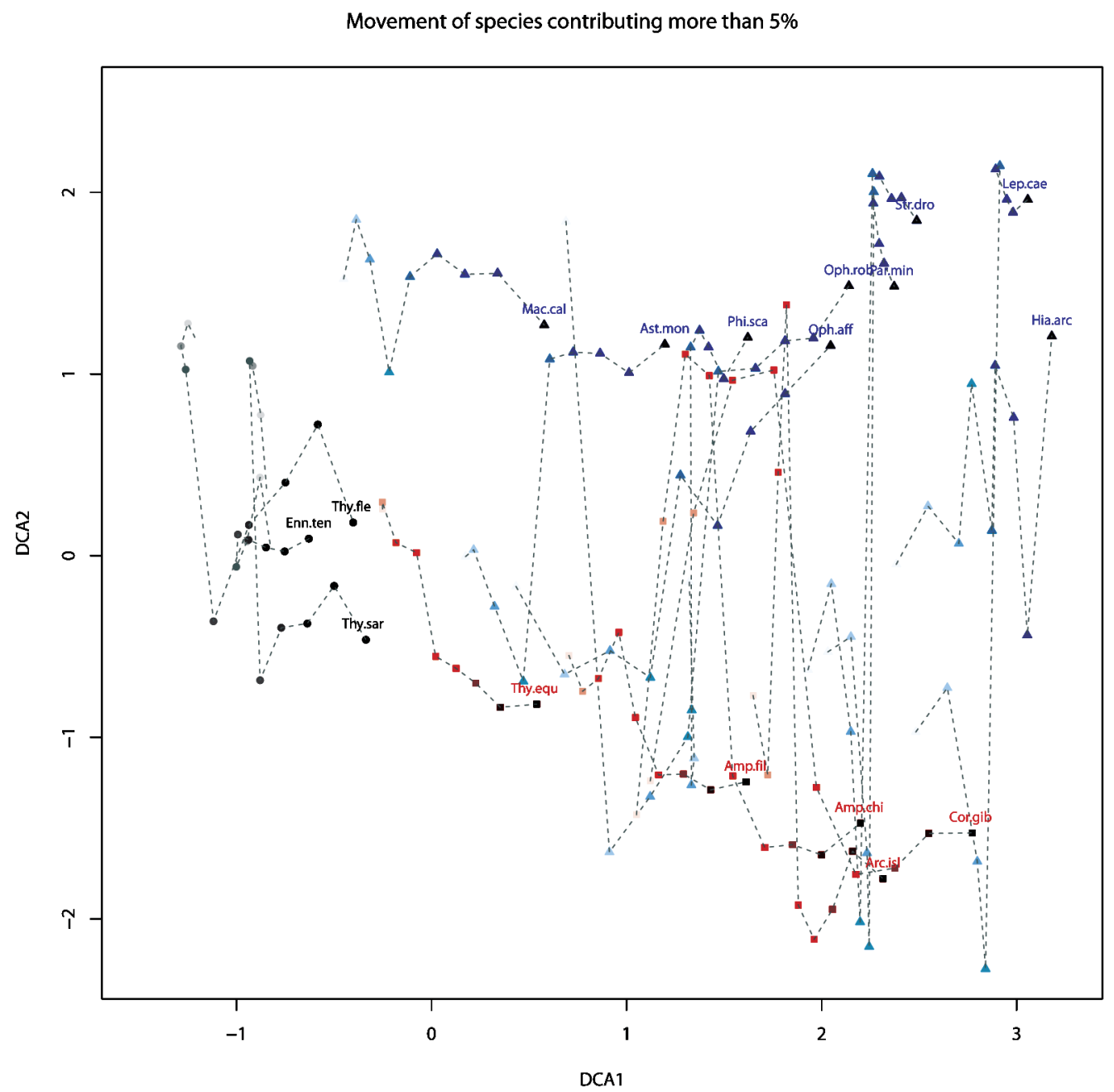

Fig. 8. Example data set 1: shifts in the DCA ordination space of estimated optima for species that contribute most strongly to differences between clusters, as a function of the range of the abundance scale $(R)$. Each species is represented by the colour and symbol shape (black, $\bullet$; blue, $\boldsymbol{\Delta}$; and red, $\mathbf{\square})$ for the cluster in which it reaches the highest mean abundance. For each species and each weighting function, the intensity of the colour of the symbol increases with increasing range of the abundance scale. Lines connect symbols that represent the same species. Results for nine weighting functions are shown: qual, R2 - R128, and raw. 


\title{
WORKED EXAMPLE 2: RESULTS
}

\author{
ABUNDANCE-OCCUPANCY RELATIONSHIPS
}

Example data set 2 was characterised by a weak, positive abundance-occupancy relationship (AOR): Kendall's $\tau=0.3207\left(p<10^{-6}, n=61\right)$ between the proportion of sites occupied and average abundance (Fig. 9). The positive AOR primarily resulted from the large number of species with low abundance and low occupancy: 47 out of the 128 species had mean cover $<1.5 \%$ and were present in $<10 \%$ ( 6 or fewer) of the sites. Seven species had average cover $>10 \%$ (Fig. 9), of which two (Blechnum spicant and Molinia caerulea) only occurred in two sites each, three had relatively low occupancy (Athyrium filix-femina occurred in 4 and Sphagnum girgensohnii and $S$. quinquefarium in 8 sites), and two were keystone species with high average cover and high occupancy (Vaccinium myrtillus occurred in all but two sites and had average cover $=28.7 \%$; Dicranum majus occurred in all but six sites and had an average cover $=13.7 \%$ ).

\section{IDENTIFICATION OF REFERENCE SITES}

To facilitate comparisons between ordination diagrams across methods and weighting functions, nine sites or clusters of sites were distinguished based on their behaviour in the ordinations: (1) 'the blue cluster' (indicated by blue triangles point-up in Figs. 10-11), which contained 3 sites with $S$. girgensohnii cover $\geq 10 \%$, of these one site with particularly distinctive behaviour, 'the blue open plot', was indicated by open symbol; (2) 'the red cluster' (indicated by red solid squares), which contained 3 sites with $S$. quinquefarium cover $\geq 10 \%$; (3) 'the violet plot' (indicated by violet solid triangle point-down), with cover of both $S$. girgensohnii and $S$. quinquefarium $\geq 10 \%$; (4) 'the green cluster' (indicated by green open diamonds), which contained 2 sites with Athyrium filix-femina cover $\geq 10 \%$; (5) 'the orange plot' (indicated by orange solid circle), with cover of both Blechnum spicant and Molinia caerulea $\geq 10 \%$; (6) 'the black open cluster' (indicated by black open circles), which contained 10 sites that in some ordinations formed a distinct cluster at high scores along ordination axes 1 ; one site in this cluster, 'the black cross plot, was distinguished from the rest because it had maximum species richness, 52; and (7) 'the black solid cluster' (indicated by black solid circles), which contained the bulk of sites, 41 in total.

\section{COMPARISON OF DCA AND GNMDS ORDINATIONS}

Kendall's $\tau$ between first axes of parallel DCA and GNMDS ordinations, i.e., for the same weighting function, varied from $\tau=0.61$ to $\tau=0.78$ (Table 4). Kendall's $\tau$ calculated between all pairs of second and third axes of parallel DCA and GNMDS ordinations (Table 4) revealed presence in Example data set 2 of at least two coenoclines (compositional gradients) in addition to the main coenocline (the first axes), but of these only the coenocline on GNMDS axis 3 was consistent across weighting functions. As shown by Procrustes correlation coefficients $r$ between twodimensional site configurations given by DCA and GNMDS axes $(r>0.80)$ as well as Kendall's $\tau$ between pairs of axes $(\tau>0.38)$ obtained for the same weighting function, this coenocline 


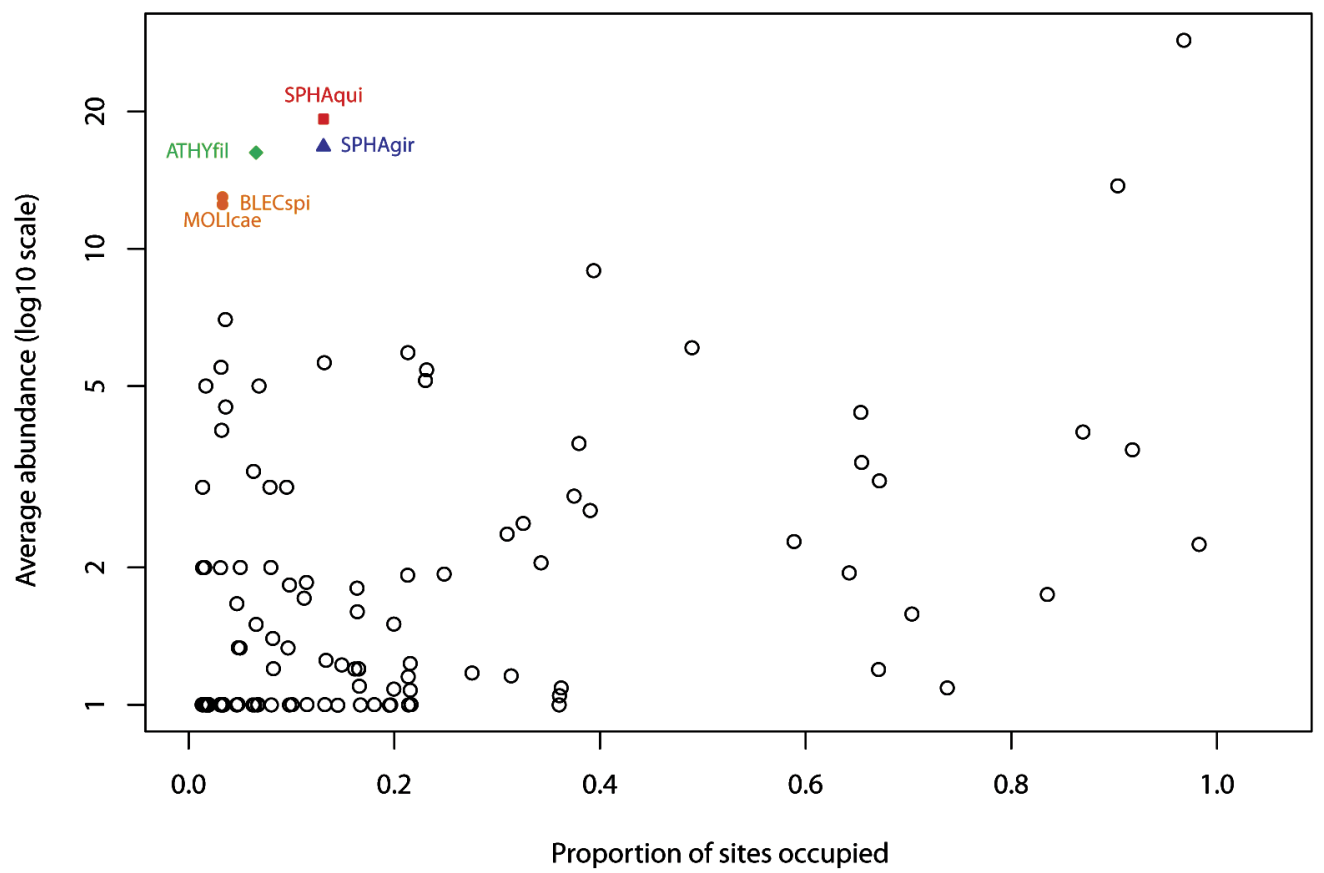

Fig. 9. Example data set 2: abundance-occupancy relationships (AOR). The relationship between occupancy (proportion of sites occupied by a species) and the species' abundance (average cover in sites where the species is present). Abbreviated names of five species, dominance by which is used as a criterion for identification of reference sites used for comparison of ordinations (Figs 10-11), are shown on the graph. ATHYfil = Athyrium filix-femina, BLECspi = Blechnum spicant; MOLIcae = Molinias caerulea; SPHAgir $=$ Sphagnum girgensohnii, SPHAqui = Sphagnum quinquefarium.

was expressed on DCA axis 2 for $R<$ approximately 10 and on DCA axis 3 for higher values of $R$. The concordance between corresponding axes was particularly high when high weight was given to abundance (Kendall's $\tau>0.55$ for $R=32$ and $r a w$; Table 4). Pair-wise Kendall's $\tau=$ 0.34-0.35 between GNMDS axis 2 and DCA axes 2 or 3 revealed that, for $R>$ approximately 5 , third coenoclines which were to some extent similar were extracted by both ordination methods. For lower values of $R$, no correspondence between GNMDS axis 2 and DCA axis 3 was found. Detailed analysis was restricted to the two coenoclines that were consistent across ordination methods and weighting functions, expressed on GNMDS axes 1 and 3, and on DCA axes 1 and 2 for $R<$ approximately 10 and on DCA axes 1 and axis 3 for higher values of $R$, respectively.

\section{DCA ORDINATIONS}

The DCA results were affected in five main ways by change in the weight given to abundance (Fig. 10). With increasing range of the abundance scale, (1) the gradient length of DCA axis 1, 

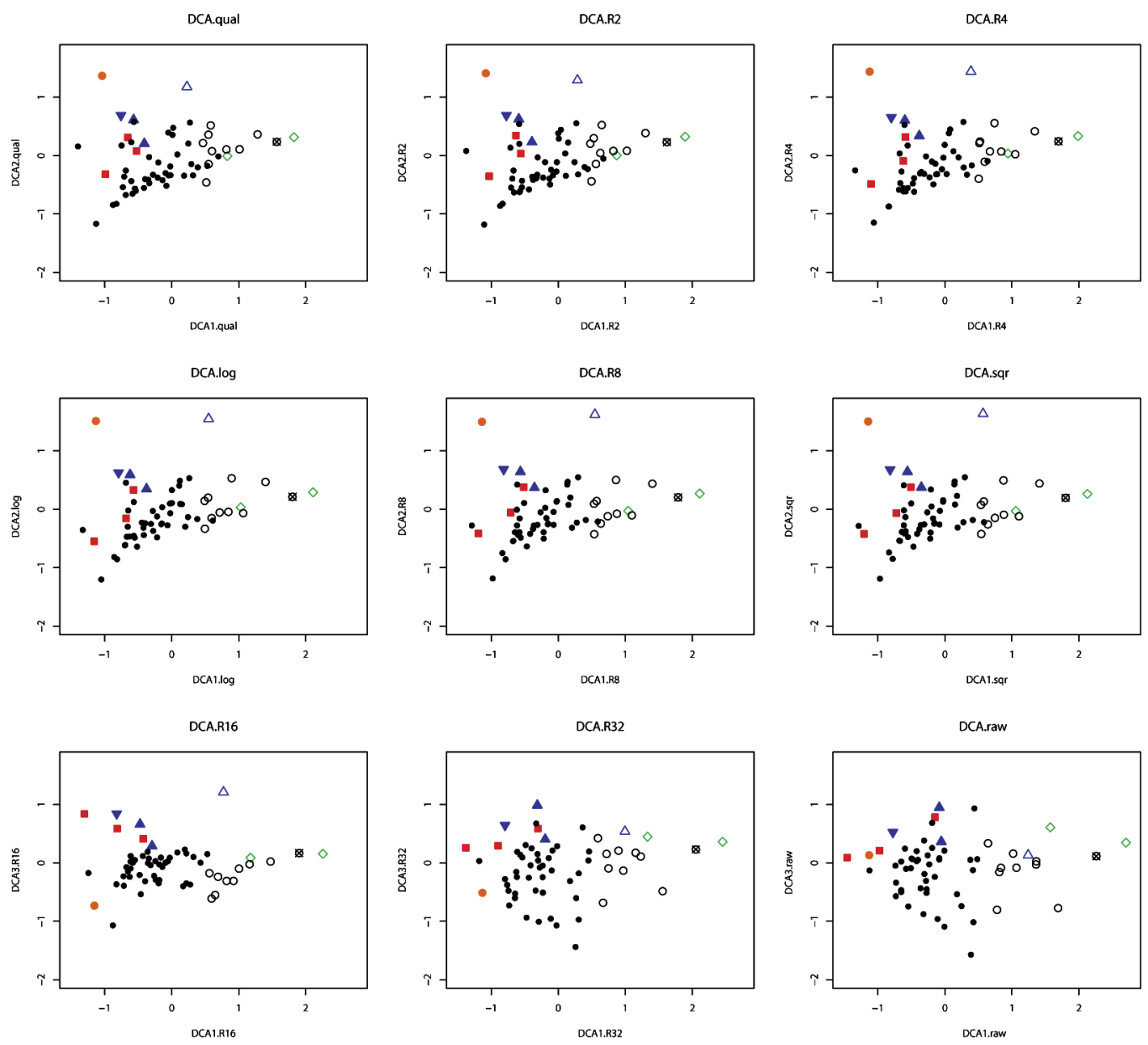

Fig. 10. Example data set 2: DCA results for different ranges of the abundance scale (weighting functions). Reference sites and clusters of sites are marked by symbols with different colors and shapes, used in a consistent way throughout all ordination diagrams. Axes are scaled in S.D. (standard deviation) units.

measured in S.D. units, increased from 3.3 to 4.3 S.D. units while no change in gradient length occurred along the secondary axes; and (2) the tendency of the orange and blue open sites to act as distinct outliers along the secondary DCA axes decreased. DCA ordination diagrams for $R=32$ and raw differed from the other ordination diagrams by (3) the tendency for sites indicated by symbols other than black open and black solid to occupy extreme positions along both DCA axes, most clearly shown for raw; (4) a small gap in the site configuration at DCA axis 1 $=0$, separating sites of the black open cluster and eight sites of the black solid cluster from the rest of black solid cluster; and (5) lack of a distinctly tongue-shaped configuration of sites in ordination space, most clearly seen when raw data were used, caused by minimal variation in site scores along the secondary axes for sites with high DCA 1 score. 

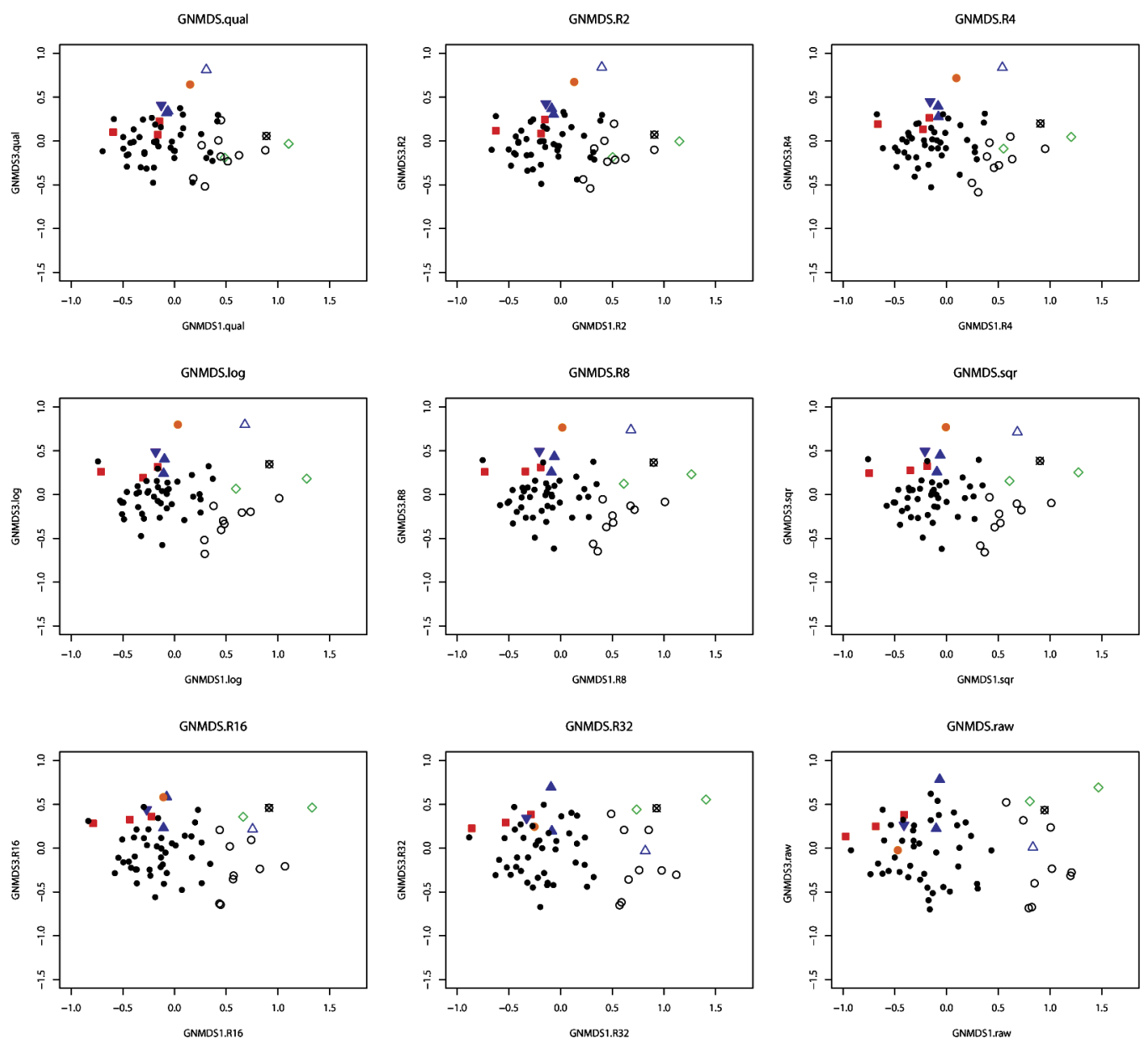

Fig. 11. Example data set 2: GNMDS results for different ranges of the abundance scale (weighting functions). Reference sites and clusters of sites are marked by symbols with different colors and shapes, used in a consistent way throughout all ordination diagrams. Axes are scaled in H.C. (half change) units.

\section{GNMDS ORDINATIONS}

Changing the range of the abundance scale by weighting impacted GNMDS ordinations partly in similar, partly in different ways than DCA (Fig. 11). DCA patterns (1-3) recurred in GNMDS to some degree while DCA patterns (4-5) were replaced by GNMDS-specific pattern (4). The main GNMDS patterns were as follows: With increasing range of the abundance scale, (1) the gradient length of GNMDS axis 1 increased from 1.8 to 2.5 H.C. units and that of GNMDS axis 3 from 1.3 to 1.5 H.C. units, resulting in a better spread of sites in the ordination diagram; (2) the orange and blue open sites, which acted as slight outliers along GNMDS axis 3 in ordinations 
Table 4. Example data set 2: comparison of DCA and GNMDS results. Range refers to the range of the abundance scale (i.e., the ratio between maximum and minimum values for presence observations) for the respective weighting functions. $r D 1 x G 1 y=$ the Procrustes correlation coefficient between two-dimensional site configurations given by DCA axes 1 and $x$ and GNMDS axes 1 and $y$. $\tau$ Dx1Gy = Kendall's rank correlation coefficients between DCA axis $x$ and GNMDS axis $y$, respectively, obtained from data sets with given weighting of abundance.

\begin{tabular}{|c|c|c|c|c|c|c|c|c|c|}
\hline Weight & Range & rD12G12 & D12G13 & rD13G13 & TD1G1 & TD2G2 & TD2G3 & TD3G2 & TD3G3 \\
\hline qual & 1.0 & 0.65 & 0.89 & 0.63 & 0.61 & 0.05 & 0.49 & 0.14 & 0.06 \\
\hline R2 & 2.0 & 0.64 & 0.90 & 0.66 & 0.63 & 0.05 & 0.48 & 0.15 & 0.07 \\
\hline R4 & 4.0 & 0.64 & 0.91 & 0.79 & 0.68 & 0.01 & 0.45 & 0.03 & 0.37 \\
\hline $\log$ & 4.3 & 0.71 & 0.90 & 0.79 & 0.73 & 0.05 & 0.39 & 0.24 & 0.35 \\
\hline R8 & 8.0 & 0.75 & 0.90 & 0.75 & 0.74 & 0.13 & 0.42 & 0.34 & 0.22 \\
\hline sqr & 8.7 & 0.77 & 0.89 & 0.74 & 0.75 & 0.16 & 0.40 & 0.34 & 0.20 \\
\hline R16 & 16.0 & 0.86 & 0.79 & 0.83 & 0.78 & 0.34 & 0.20 & 0.17 & 0.43 \\
\hline R32 & 32.0 & 0.82 & 0.73 & 0.90 & 0.78 & 0.35 & 0.05 & 0.21 & 0.61 \\
\hline raw & 75.0 & 0.77 & 0.77 & 0.87 & 0.75 & 0.35 & 0.14 & 0.21 & 0.56 \\
\hline
\end{tabular}

with low $R$, entered the bulk of sites and eventually obtained scores along GNMDS 3 close to 0.0 ; and (3) the tendency for sites indicated by symbols other than black open and black solid to occupy extreme positions along GNMDS axis 3, clearly visible for $R \geq 4$, whereby positions of sites of the blue and green clusters were shifted towards the high-score end of GNMDS axis 3; and (4) the position of a slight gap in the site configuration along GNMDS axis 1 changed from GNMDS $1 \approx 0.0$ to GNMDS $1 \approx 0.5$, so that the black open cluster was clearly from the black solid cluster when high weight was given to abundance.

\section{DISCUSSION}

Results obtained for the two example data sets show that ordination results are strongly dependent on the choice of ordination method. While for Example data set 1 parallel DCA and GNMDS ordinations are largely consistent, parallel ordinations of Example data set 2 differ considerably. Example data set 2 illustrates why parallel ordinations should always be performed (R. Økland 1990a, 1996): point patterns in ordination space may be artifactual, strongly influenced by the ordination algorithm, rather than appropriate representations of data structure. The 'tongue effect' (Minchin 1987) on axes 2 and 3 of DCA ordinations of Example data set 2 (DCA pattern 5) is a direct result of the detrending-by-segments procedure which removes any systematic relationship between axes of higher order and axes of lower order in DCA (R. Økland 1990a, 1990b). When sites are aligned on a tongue in a DCA ordination diagram, the DCA axis in question does not, as such, provide any information about how sites on the tongue (high scores along DCA axis 1) are related to the other sites (low scores along axis 1) along this 
coenocline. In our case, parallel GNMDS ordinations suggest that the position of 'tongue sites' near the middle of the secondary DCA axis is reasonable, but counterexamples are abundantly found in the literature (see R. Økland 1990a). DCA ordination results for Example data set 2 also exemplify the so-called instability problem of DCA (Oksanen 1988, R. Økland 1990a), that small perturbations of the data such as a small change of the weighting function, may change the order of appearance of DCA axes.

The results also show that ordination results are strongly dependent on the weighting of qualitative vs. quantitative information in the species-abundance matrix. For Example data set 1 , the gradient structure obtained for qualitative data is hardly recognizable in the results obtained for raw data: the two extreme weighting functions thus reveal complementary community structures that are bridged by a gradient of intermediates along which three clusters of sites become increasingly distinct (or disjunct; Gauch 1982). Also for Example data set 2 different gradient structures are revealed by different weighting functions. While two strong coenoclines are consistently revealed by the two ordination methods, the ranking of these by DCA varies with weighting function. Furthermore, when low weight is given to abundance $(R$ $<5$ ), completely different additional coenoclines are revealed, by DCA axis 3 and GNMDS axis 2 , respectively.

Results obtained for Example data set 2 accord with previous findings by Eilertsen et al. (1990) and R. Økland et al. (1990) that estimates of compositional turnover (gradient length) by DCA axes re-scaled in S.D. units tend to increase with increasing range of the abundance scale. However, this does not necessarily be the case: for Example data set 1 no variation in gradient length along DCA axes occurs, apparently because the black cluster becomes tighter when the weight attributed to abundance is increased. Results obtained for both data sets show that estimates of compositional turnover by GNMDS axes re-scaled in H.C. units also tend to increase with increasing range of the abundance scale. Furthermore, our results indicate that suggested figures for the relationship between the S.D. and H.C. units, of 1.18 (Hill 1979) and 1.39 (Gauch 1973b) S.D. units per H.C. unit, do not in general apply to real data sets: values of 1.4-1.7 S.D. units per H.C. units are obtained for our example data sets, without systematic differences between weighting functions.

Species' contribution analysis for Example data set 1 reveal systematic relationships between ordination results, the weight given to abundance, and the properties of the species. The three clusters in the ordination diagrams of Figs. 5-6 represent three species assemblages, which become increasingly distinct when quantitative aspects of abundance variation are emphasized more strongly. The three clusters have some species in common, but their core species have abundance peaks within the respective clusters. Although disjunctions in the ordination diagrams appear gradually, they become distinct at intermediate ranges of the abundance scale $(R=8-16)$. 'Intermediate' weighting of abundance is often considered to be an optimal compromise between emphasis on qualitative and quantitative properties of the data set (e.g., van der Maarel 1979, Rydgren 1993, Thorne et al. 1999). However, a wide range of weighting functions, including the frequently used fourth root (e.g., Olsgard 1993, Thorne et al. 1999), can be considered as 'intermediate'. Distinct clusters are not present in ordinations of abundances weighted by the fourth-root function in our example.

A widely held belief is that highly abundant species will determine the ordination structure completely if their abundance is not down-weighted (e.g., Hill \& Gauch 1980). Our results show that this is not necessarily the case: this explanation is too simplistic to account for the contributions of species to differences in ordinations obtained for different weighting functions in our Example data set 1. The observed patterns can, however, be explained with reference to the hierarchical continuum concept of Collins et al. (1993), by which species are divided into four categories by a combination of their average abundance and the proportion of sites 
they occupy. These categories are the numerically dominant 'core' species that occupy a high proportion of sites and have a high mean abundance in these sites; the 'satellite' species that are found at few sites with low abundance; the 'urban' species that occupy a low proportion of sites but reach high abundance in the sites in which they occur; and the 'rural' species with low mean abundance in presence sites but that are found in a high proportion of sites. Results obtained for our Example data set 1 show that the highly dominant and most prevalent 'core' species E. tenuis influence ordinations but that other species also contribute: not even the patterns of ordinations obtained for the strongest weighting of abundance are dominated by a few core species.

Our results support the view of Austin \& Greig-Smith (1968) and van der Maarel (1979), among others, that relatively rare species and species with moderate mean abundance can contribute importantly to the structure of a data set, especially if the sampled community is markedly heterogeneous. An example of this is the 'urban' gastropod L. caeca, which is only present at three sites in Example data set 1, but that nevertheless contributed substantially to formation of the blue cluster. The importance of 'urban' species for the structure extracted by ordination methods is even more clearly shown by Example data set 2: sites dominated by the five 'urban' species (which make up a well-delimited group shown by coloured solid symbols in Fig. 9, and which dominate in reference sites identified by corresponding coloured symbols in Figs. 10-11) are the most responsive to changes in the weighting function. This is most strongly seen in DCA, which is based upon chi-square dissimilarities between sites, which particularly strongly emphasize rare, highly abundant species and sites in which such species have high abundance (Minchin 1987, R. Økland 1990a). This pattern is less strong in GNMDS because the Bray-Curtis dissimilarity measure treats all species equally, regardless of their abundanceoccupancy relationships (R. Økland 1986a, Faith et al. 1987).

Our results support the view of Lengyel et al. (2012) that rare, 'specialist' species (i.e., 'urban' and 'satellite' species) can impact ordination structure more strongly than 'generalists' (i.e., 'core' and 'rural' species), in particular if presence-absence data are used. Overall, more than one third of the species in our Example data set 1 contributed substantially to the formation of structure in the ordinations, either at weak, intermediate or strong weights given to high abundance. Even 'satellite' species were represented among these species. Among the five species that contributed most to the ordination structure for Example data set 1, we found two 'rural' species (O. affinis and T. equalis), two 'urban' species (C. gibba and L. caeca), only one 'core' species (E. tenuis), but no 'satellite' species. This indicates that 'rural' and 'urban' species are likely to be more, or at least equally, important in defining ordination axes as 'core' species, and that the strength of the influence by such species on ordination axes will increase when quantitative aspects of the data are more strongly emphasized. Furthermore, we argue that ecological specialists of the 'urban' species type will have particularly strong influence on DCA ordination axes. The fact that all types of species, even rare or low-abundant ones, can contribute to the observed structure in ordination diagrams emphasizes the importance of keeping all species in the analysis and not removing rare species, which is a common practice in multivariate analysis of ecological data (cf., R. Økland 1990a, Gogina et al. 2010).

The extent to which results obtained by applying the MPO procedure to our example data sets apply to communities in general depends on the degree to which these data sets are representative, or 'typical', of species-abundance data sets. Two 'typical' properties of speciesabundance data from natural communities are right-skewed species richness distributions, "it is common to be rare and rare to be common" (Raunkiær 1918, Hanski 1982, Bratli et al. 2006) and positive abundance-occupancy relationships (Brown 1984; Ellingsen et al. 2007, Buckley $\&$ Freckleton 2010). Both of our example data sets have these two properties. More than half of the species occupy less than $20 \%$ and $10 \%$ of the sampled sites in Example data sets 1 and 2, 
respectively, and most of these have consistently low abundance, and can therefore be considered 'satellite' species. Only one species in Example data set 1 (E. tenuis) and two species in Example data set 2 (V. myrtillus and D. majus) are truly 'core' species while the remaining species can be typified as 'urban' and 'rural' species. Both data sets have positive AOR, but AOR is less positive in Example data set 2 due to presence of several 'urban' species.

The MPO procedure described in this paper is an extension of the PO strategy. Our two example data sets exemplify variation from high to lower similarity of configuration between DCA and GNMDS ordinations obtained for the same weighting function. In the former case, the PO approach reduces the uncertainty with respect to reliability of ordinations (R. Økland 1990a, 1996) while in the latter case this approach suggests that careful additional analyses are needed. Our results show that van der Maarel's (1982) suggestion that abundance-weighting is more important for extracting the structure of the species-abundance matrices than the ordination method does not hold true in general, as also pointed out by Rydgren (1993). Rydgren (1993) hypothesized that weighting of species abundances becomes less important and choice of ordination method more important with increasing size of the species-abundance matrix. Although results for our two data sets accord with this hypothesis, more data sets have to be compared to judge if this hypothesis generally holds true.

No explicit criteria can be used for evaluation of ordination results obtained for field data sets because the 'true', underlying data structure is not known (Minchin 1987, R. Økland 1990a). Assessments of appropriateness therefore have to rely on expert judgment by experienced ecologists (Austin \& Greig-Smith 1968, Smartt et al. 1974, van der Maarel 1979) or, alternatively, by taking high correlations of axes with environmental variables as an indication of good performance (T. Økland 1996, Olsgard et al. 1997, Liu et al. 2008, Wilson 2012).

Ecological interpretation of our results is beyond the scope of this paper, but Fig. 12 shows that several recorded environmental variables were highly correlated ( $\mathrm{p}$ values $\leq 0.05$ ) with the DCA axes obtained for Example data set 1. It is evident that the strong differences between ordination results obtained for different weighting functions have important consequences for the ecological interpretation of these ordination results (van Son et al, unpublished data). The fact that different ordinations, with different ecological interpretations, can be obtained from essentially the same data set represents an important challenge because it may impede generalization of which ecoclines are important (Jackson 1993, see also Wilson 2012).

Each species-abundance matrix has unique properties. Our example shows that the full range of these properties can only be revealed if an analytic framework with a broad perspective is adopted. Our results demonstrate that no universal, optimal weighting of abundances exist (see van der Maarel 1979), and that general guidelines for selecting the most appropriate weighting of the data cannot be worked out (cf. Smartt et al. 1974). However, the ratio between quantitative and qualitative information in the raw data set, each expressed as total sums of squares of respective species-abundance matrices (e.g., Noy-Meir et al. 1975), standardized in some way by the number of species and sites, may perhaps provide a hint whether a strong or mild weighting of abundance is likely to give rise to a 'consensus' regarding the underlying community structure (Rydgren 1993). Nevertheless, our results demonstrate that to search for the optimal weighting function is to head in the wrong direction: instead one should acknowledge that data sets which contain qualitative as well as quantitative variation do not contain one 'true' gradient structure but rather a continuum of gradient structures that depend on the weighting of presence vs. abundance. An important element of explorative data analysis (general-purpose studies; R. Økland 1996) should therefore be to elucidate this continuum of gradient structures. At the outset, all of these structures are equally valid, but all do not necessarily have equally high relevance for specific-purpose studies.

Abundance-occupancy relationships and their revelation of the core-urban-rural-satellite 


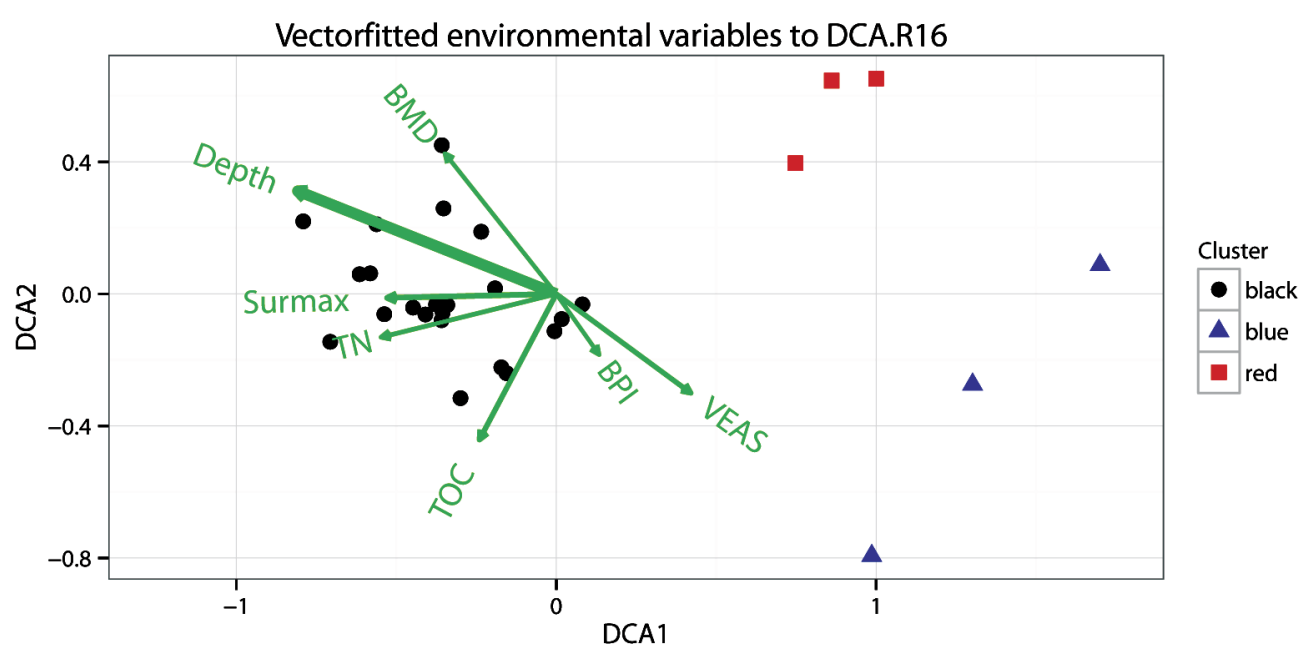

Fig. 12. Example data set 1: vector fitting of environmental variables to the DCA ordination with abundance range of 16 . The direction and length of the vectors are determined by the envfit() function in the vegan package. The thickness of the vectors is scaled proportionally to Kendall's $\tau$ correlation with DCA1. Only vectors with a p-value $\leq 0.05$ are shown. Sites are coded by the color and symbol shape (black, $\bullet$; blue, $\mathbf{\Delta}$; and red, $\boldsymbol{\square}$ ) of the cluster to which they belong. BMD = biogenic mixing depth; BPI = bathymetric position index; Depth = ocean depth; Surmax = maximum current speed at the ocean surface; TOC = total organic carbon; $\mathrm{TN}=$ total nitrogen; VEAS = distance to waster water effluent.

distribution patterns of species provide both additional insights into the properties of communities and explanations for the behaviour of ordinations subjected to different abundance ranges. 'Urban' species in particular, but also 'rural' species are more or equally important as 'core' species in defining the gradient structure of species-abundance matrices. This is not surprising given that fact that true 'core' species are few and far-between.

The use of multiple abundance ranges when performing ordination analysis provides additional insight to the gradient structure of the species-abundance matrix. Especially, no and strong weight given to abundance provide complimentary information. Application of parallel ordination either increases the reliability of the result or raise awareness about the need for additional analyses.

We argue that every general-purpose study by ordination methods will benefit from adopting a MPO procedure because this analytical strategy highlights the variation in properties of the species-abundance matrix. Furthermore, we recommend researchers that apply multivariate methods to report more than just one ordination result. Reporting of results for one strong, one intermediate, and one weak (presence/absence, or close to presence/absence) weighting of abundance is likely to provide important additional insights into the structure of the community in question, compared to the common practice of applying one weighting function only. In order to dig deeper into the relationships between data-set properties and expected results from parallel ordinations with different weighting functions, a broad range of simulated data sets with known structure should be subjected to analysis. 


\section{ACKNOWLEDGEMENTS}

We are grateful to M. Kaurin, F. Melsom, R. Amundsen, and B. Kaasa for assistance in the lab, Øystein Stokland for assistance in identifying mollusc species, S. Mazzoni, T. Bekkby, R. Heimstad, PA Aarrestad as well as three anonymous referees for invaluable comments on earlier versions of this manuscript, T. Bakke, K. Hylland, G. Borgersen, the late F. Olsgard, master students for assisting in the field work, and the crew on R/V T. Braarud. This work is part of T.C. van Son's PhD work.

\section{REFERENCES}

Austin, M.P. \& Greig-Smith, P. 1968. The application of quantitative methods to vegetation survey: II. Some methodological problems of data from rain forest. J. Ecol 56: 827-844.

Beals, E.W. 1973. Ordination: Mathematical elegance and ecological naivete. J. Ecol. 61: 2335.

Bratli, H., Økland, T., , Økland, R.H., Dramstad, W.E., Elven, R., Engan, G., Fjellstad, W., Heegaard, E., Pedersen, O. \& Solstad, H. 2006. Patterns of variation in vascular plant species richness and composition in SE Norwegian agricultural landscapes. Agric. Ecosyst. \& Environ. 114: $270-286$.

Brown, J.H. 1984. On the relationship between abundance and distribution of species. Am. Nat. 124: 255-279.

Buckley, H.L. \& Freckleton, R.P. 2010. Understanding the role of species dynamics in abundanceoccupancy relationships. J Ecol. 98: 645-658.

Cao, Y. \& Epifanio, J. 2010. Quantifying the responses of macroinvertebrate assemblages to simulated stress: are more accurate similarity indices less useful? Meth. Ecol. Evol. 1: 380-388.

Clarke, K. 1993. Non-parametric multivariate analyses of changes in community structure. Aus. J. Ecol. 18: 117-143.

Clymo, R. 1980. Preliminary survey of the peat-bog Hummell Knowe Moss using various numerical methods. Vegetatio 42: 129-148.

Collins, S. L., Glenn, S.M. \& Roberts, D.W. 1993. The hierarchical continuum concept. J. Veg. Sci. 4: 149-156.

De'ath, G. 1999. Extended dissimilarity: a method of robust estimation of ecological distances from high beta diversity data. Pl. Ecol. 144: 191-199.

Eilertsen, O., Økland, R.H., Økland, T. \& Pedersen, 0.1990. Data manipulation and gradient length estimation in DCA ordination. J. Veg. Sci. 1: 261-270.

Ellingsen, K.E. \& Gray, J.S. 2002. Spatial patterns of benthic diversity: is there a latitudinal gradient along the Norwegian continental shelf? J. Anim. Ecol. 71: 373-389.

Ellingsen, K.E., Hewitt, J.E. \& Thrush, S.F. 2007. Rare species, habitat diversity and functional redundancy in marine benthos. J. Sea Res. 58: 291-301.

Faith, D.P., Minchin, P.R. \& Belbin, L. 1987. Compositional dissimilarity as a robust measure of ecological distance. Vegetatio 69: 57-68.

Gauch, H.G., Jr. 1982. Multivariate Analysis in Community Ecology. Cambridge University 
Press.

Gauch, H.G., Jr. 1973a. A quantitative evaluation of the Bray-Curtis ordination. Ecology 54: 829-836.

Gauch, H.G., Jr. 1973b. The relationship between sample similarity and ecological distance. Ecology 54: 618-622.

Goodall, D.W. 1954. Vegetational classification and vegetational continua. Festschr. Aichinger 1: $168-182$.

Gogina, M., Glockzin, M. \& Zettler M.L. 2010. Distribution of benthic macrofaunal communities in the western Baltic Sea with regard to near-bottom environmental parameters. 1. Causal analysis. J. Mar. Syst. 79: 112-123.

Halvorsen, R. 2012. A gradient analytic perspective on distribution modeling. Sommerfeltia 35: 1-165.

Hanski, I. 1982. Dynamics of regional distribution: the core and satellite species hypothesis. Oikos 38: 210.

Heino, J., Muotka, T., Mykrä, H., Paavola, R., Hämäläinen, H. \& Koskenniemi, E. 2003. Defining macroinvertebrate assemblage types of headwater streams: Implications for bioassessment and conservations. Ecol. App. 13: 842-852.

Hill, M.O. 1973. Reciprocal averaging: An eigenvector method for ordination. J. Ecol. 61: 237249.

Hill, M. O. 1979. DECORANA - A FORTRAN program for detrended correspondence analysis and reciprocal averaging. Ithaca.

Hill, M.O., Bell, N., Bruggeman-Nannenga, M.A., Brugués, M., Cano, M.J., Enroth, J., Flatberg, K.I., Frahm, J.P., Gallego, M.T., Garilleti, R., Guerra, J., Hedenäs, L., Holyoak, D.T., Hyvönen, J., Ignatov, M.S., Lara, F., Mazimpaka, V., Muñoz, J. \& Söderström, L. 2006. An annotated checklist of the mosses of Europe and Macaronesia. J. Bryol. 28: 198-267.

Hill, M.O. \& Gauch, H.G. Jr. 1980. Detrended correspondence analysis: an improved ordination technique. Vegetatio 42: 47-58.

Jackson, D.A. 1993. Multivariate analysis of benthic invertebrate communities: the implication of choosing particular data standardizations, measures of association, and ordination methods. Hydrobiologia 268: 9-26.

Kenkel, N.C. 2006. On selecting an appropriate multivariate analysis. Canadian Journal of Pl. Sci. 86: 663-676.

Krog, H., Østhagen, H. \& Tønsberg, T. 1994. Lavflora. Norske busk- og bladlav. Ny revidert utgave ved Hildur Krog og Tor Tønsberg, ed. 2. Universitetsforlaget, Oslo.

Legendre, P. \& Legendre, L. 1998. Numerical ecology, 2nd Edition. Elsevier, Amsterdam.

Lengyel, A., Csiky, J. \& Botta-Dukát, Z. 2012. How do locally infrequent species influence numerical classification? A simulation study. Comm. Ecol. 13: 64-71.

Lid, J. \& Lid, D.T. 2005. Norsk flora. 7 utgåve ved R. Elven. Det Norske Samlaget, Oslo.

Liu, H., Økland, T., Halvorsen, R., Gao, J., Liu, Q., Eilertsen, O. \& Bratli, H. 2008. Gradient analyses of forests ground vegetation and its relationships to environmental variables in five subtropical forest areas, S and SW China. Sommerfeltia 32: 1-196.

Lundblad, E.R., Wright, D.J., Miller, J., Larkin, E.M., Rinehart, R., Naar, D.F., Donahue, D.T., Anderson, S.M. \& Battista, T. 2006. A Benthic Terrain Classification Scheme for American Samoa. Mar. Geod. 29: 89-111.

van der Maarel, E. 1979. Transformation of cover-abundance values in phytosociology and its effects on community similarity. Vegetatio 39: 97-114.

van der Maarel, E. 1982. On the manipulation and editing of phytosociological and ecological data. Vegetatio 50: 71-76.

Mahecha, M.D., Martínez, A., Lischeid, G. \& Beck, E. 2007. Nonlinear dimensionality reduction: 
Alternative ordination approaches for extracting and visualizing biodiversity patterns in tropical montane forest vegetation data. Ecol. Inf. 2: 138-149.

Minchin, P.R. 1987. An evaluation of the relative robustness of techniques for ecological ordination. Vegetatio 69:89-107.

Noy-Meir, I., Walker, D. \& Williams, W.T. 1975. Data Transformations in Ecological Ordination: II. On the Meaning of Data Standardization. J. Ecol. 63: 779-800.

Økland, R.H. 1986a. Rescaling of ecological gradients. I. Calculation of ecological distance between vegetation stands by means of their floristic composition. Nord. J. Bot. 6: 651-660.

$\emptyset \mathrm{kland}$, R.H. 1986b. Reseating of ecological gradients. II. The effect of scale on symmetry of species response curves. Nord. J. Bot. 6: 661-670.

Økland, R.H. 1990a. Vegetation ecology: theory, methods and applications with reference to Fennoscandia. Sommerfeltia 1:1-233.

Økland, R.H. 1990b. A phytoecological study of the mire Northern Kisselbergmosen, SE Norway. II. Identification of gradients by detrended (canonical) correspondence analysis. Nord. J. Bot. 10:79-108.

Økland, R.H. 1996. Are ordination and constrained ordination alternative or complementary strategies in general ecological studies? J. Veg. Sci. 7: 289-292.

Økland, R.H. \& Eilertsen, 0. 1993. Vegetation-environment relationships of boreal coniferous forests in the Solhomfjell area, Gjerstad, S Norway. Sommerfeltia 16:1-254.

Økland, R.H., Eilertsen, O. \& Økland, T. 1990. On the relationship between sample plot size and beta diversity in boreal coniferous forests. Vegetatio 87:187-192.

Økland, R. H., Økland, T. \& Rydgren, K. 2001. Vegetation-environment relationships of boreal spruce swamp forests in Østmarka Nature Reserve, SE Norway. Sommerfeltia 29:1-190.

$\emptyset \mathrm{kland}, \mathrm{T}$. 1996. Vegetation-Environment relationships of boreal spruce forests in ten monitoring reference areas in Norway. Sommerfeltia 22:1-349.

Økland, T., Rydgren, K., Økland, R.H., Storaunet, K.O. \& Rolstad, V. 2003. Variation in environmental conditions, understorey species richness, abundance and composition among natural and managed Picea abies forest stands. For. Ecol. Man 177: 17-37.

Oksanen, J. 1988. A note on the occasional instability of detrending in correspondence analysis. Vegetatio 74: 29-32.

Oksanen, J., Blanchet, F.G., Kindt, R., Legendre, P., O'Hara, R.B., Simpson, G.L., Solymos, P., Stevens, M.H.H. \& Wagner, H. 2012. Community ecology package, "vegan" version 2.0-4.

Olsgard, F. 1993. Do toxic algal blooms affect subtidal soft-bottom communities? Mar. Ecol. Prog. Ser. 102: 269-286.

Olsgard, F. \& Gray, J.S. 1995. A comprehensive analysis of the effects of offshore oil and gas exploration and production on the benthic communities of the Norwegian continental shelf. Marine Ecology Progress Series 122: 277-306.

Olsgard, F., Somerfield, P. \& Carr, M. 1997. Relationships between taxonomic resolution and data transformations in analyses of a macrobenthic community along an established pollution gradient. Mar. Ecol. Prog. Ser. 149: 173-181.

Orlóci, L. 1978. Multivariate analysis in vegetation research. Second ed. Junk, The Hague.

Palmer, M.W. 1993. Putting things in even better order: The advantages of canonical correspondence analysis. Ecology 74:2215-2230.

Peet, R.K., Knox, R.G., Case, J.S. \& Allen, R.B. 1988. Putting things in order: The advantages of detrended correspondence analysis. Am Nat 131: 924-934.

Podani, J. 1989. Comparison of ordinations and classifications of vegetation data. Vegetatio 83:11-128.

Raunkiær, C. 1918. Recherches statistiques sur les formations végétales. Biologiske meddelelser udgivne af Det kongelige danske videnskabernes selskab 1:1-80. 
R Development Core Team. 2012. R: A Language and Environment for Statistical Computing. R Foundation for Statistical Computing, Vienna, Austria.

Rydgren, K. 1993. Herb-rich spruce forests in W Nordland, N Norway: an ecological and methodological study. Nord. J. Bot. 13: 667-690.

Smartt, P.F.M., Meacock, S.E. \& Lambert, J.M. 1974. Investigations into the properties of quantitative vegetational data: I. Pilot study. J.Ecol. 62: 735-759.

Swan, J.M.A. 1970. An examination of some ordination problems by use of simulated vegetational data. Ecology. 51: 89-102.

Thorne, R.S.J., Williams, W.P. \& Cao, Y. 1999. The influence of data transformations on biological monitoring studies using macroinvertebrates. Water Res. 33: 343-350.

Wartenberg, D., Ferson, S. \& Rohlf, F.J. 1987. Putting things in order: A critique of detrended correspondence analysis. Am Nat 129: 434-448.

Whittaker, R.H. 1956. Vegetation of the Great Smokey Mountains. Ecol. Monogr. 26: 1-80.

Whittaker, R.H. 1967. Gradient analysis of vegetation. Biol. Rev. 42: 207-264.

Wildi, 0.1980. Management and multivariate analysis of large data sets in vegetation research. Vegetatio 42: 175-180.

Wilson, J.B. 2012. Species presence/abundance sometimes represents a plant community as well as species abundances do, or better. J. Veg. Sci. 23: 1013-1023.

Wright, I.A N.A., Chessman, B.C., Fairweather, P.G. \& Benson L.E.E.J. 1995. Measuring the impact of sewage effluent on the macroinvertebrate community of an upland stream: the effect of different levels of taxonomic resolution and quantification. Aus. J. Ecol. 20: 142-149. 


\section{APPENDIX 1: EXAMPLE DATA SET 1: COMPLETE SPECIES LIST}

Nomenclature used: www.species-identification.org.

\begin{tabular}{|c|c|c|c|}
\hline $\begin{array}{l}\text { Abbrevi- } \\
\text { ated } \\
\text { name }\end{array}$ & Scientific name & Family & $\begin{array}{l}\text { Higher } \\
\text { taxonomic } \\
\text { group }\end{array}$ \\
\hline Abr.alb & Abra alba & Semelidae & Bivalvia \\
\hline Abr.nit & Abra nitida & Semelidae & Bivalvia \\
\hline Apo.pes & Aporrhais pespelecani & Aporrhaidae & Gastropoda \\
\hline Arc.isl & Arctica islandica & Arcticidae & Bivalvia \\
\hline Amp.chi & Amphiura chiajei & Amphiuridae & Ophiuroidea \\
\hline Amp.fil & Amphiura filiformis & Amphiuridae & Ophiuroidea \\
\hline Amp.squ & Amphifolis squamata & Amphiuridae & Ophiuroidea \\
\hline Ant.ent & Antalis entalis & Dentaliidae & Bivalvia \\
\hline Ast.ell & Astarte elliptica & Astartidae & Bivalvia \\
\hline Ast.mon & Astarte montagui & Astartidae & Bivalvia \\
\hline Ast.sul & Astarte sulcata & Astartidae & Bivalvia \\
\hline Bri.lyr & Brissopsis lyrifera & Spatangidae & Echinoidea \\
\hline Buc.und & Buccinum undatum & Buccindae & Gastropoda \\
\hline Cau.cla & Caudofoveata (class) & & Caudofoveata \\
\hline Cor.gib & Corbula gibba & Corbulidae & Bivalvia \\
\hline Cus.cus & Cuspidaria cuspidata & Cuspidaridae & Bivalvia \\
\hline Cyl.alb & Cylichna alba & Cylichnidae & Bivalvia \\
\hline Dia.min & Diaphana minuta & Diaphanidae & Bivalvia \\
\hline Ech.cor & Echinocardium cordatum & Spatangidae & Echinoidea \\
\hline Ech.fla & Echinocardium flavescens & Spatangidae & Echinoidea \\
\hline Enn.ten & Ennucula tenuis & Nuculidae & Bivalvia \\
\hline Eus.mon & Euspira montagui & Naticidae & Gastropoda \\
\hline Hia.arc & Hiatella arctica & Hiatellidae & Bivalvia \\
\hline Kur.bid & Kurtiella bidentata & Montacutidae & Bivalvia \\
\hline Lep.cae & Lepeta caeca & Lepetidae & Gastropoda \\
\hline Mac.cal & Macoma calcarea & Tellinidae & Bivalvia \\
\hline Mya.tru & Mya truncata & Myidae & Bivalvia \\
\hline Myt.edu & Mytilus edulis & Mytilidae & Bivalvia \\
\hline Nuc.per & Nuculana pernula & Nuculanidae & Bivalvia \\
\hline Oph.acu & Ophiopholis aculeata & Ophiactidae & Ophiuroidea \\
\hline Oph.aff & Ophiura affinis & Ophiolepidae & Ophiuroidea \\
\hline Oph.alb & Ophiura albida & Ophiolepidae & Ophiuroidea \\
\hline Oph.fra & Ophiothrix fragilis & Ophiotrichidae & Ophiuroidea \\
\hline Oph.oph & Ophiura ophiura & Ophiolepidae & Ophiuroidea \\
\hline Oph.rob & Ophiura robusta & Ophiolepidae & Ophiuroidea \\
\hline Par.min & Parvicardium minimum & Cardiidae & Bivalvia \\
\hline Par.ova & Parvicardium ovale & Cardiidae & Bivalvia \\
\hline Phi.sca & Philine scabra & Philinidae & Gastropoda \\
\hline Pse.pes & Pseudamussium peslutrae & Petinidae & Bivalvia \\
\hline
\end{tabular}




$\begin{array}{llll}\text { Ris_fam } & \text { Rissoidae (family) } & \text { Rissoidae } & \text { Gastropoda } \\ \text { Str.dro } & \text { Strongylocentrotus droebachiensis } & \text { Strongylocentrotidae } & \text { Echinoidea } \\ \text { Tel.fer } & \text { Tellimya ferriginosa } & \text { Montacutidae } & \text { Bivalvia } \\ \text { Thy.equ } & \text { Thyasira equalis } & \text { Thyasiridae } & \text { Bivalvia } \\ \text { Thy.fle } & \text { Thyasira flexuosa } & \text { Thyasiridae } & \text { Bivalvia } \\ \text { Thy.gou } & \text { Thyasira gouldi } & \text { Thyasiridae } & \text { Bivalvia } \\ \text { Thy.sar } & \text { Thyasira sarsi } & \text { Thyasiridae } & \text { Bivalvia }\end{array}$

\section{APPENDIX 2: EXAMPLE DATA SET 2: COMPLETE SPECIES LIST, WITH AFFILIATION TO HIGHER TAXONOMIC GROUP}

Nomenclature of vascular plants follows Lid \& Lid (2005), of bryophytes Hill et al. (2006) and of lichens Krog et al. (1994).

\section{Scientific name}

Aulacomnium palustre

Brachythecium salebrosum

Cirriphyllum piliferum

Dicranum fuscescens

Dicranum majus

Dicranum polysetum

Dicranum scoparium

Eurhynchium striatum

Fissidens adianthoides

Herzogiella striatella

Hylocomiastrum umbratum

Hylocomium splendens

Hypnum cupressiforme

Mnium hornum

Mnium spinosum

Paraleucobryum longifolium

Plagiomnium affine

Plagiothecium denticulatum

Plagiothecium laetum agg.

Plagiothecium undulatum

Pleurozium schreberi

Pohlia nutans

Polytrichastrum formosum

Polytrichum commune agg.

Pseudotaxiphyllum elegans

Ptilium crista-castrensis

Rhizomnium punctatum

\section{Higher taxonomic group}

Bryophyta

Bryophyta

Bryophyta

Bryophyta

Bryophyta

Bryophyta

Bryophyta

Bryophyta

Bryophyta

Bryophyta

Bryophyta

Bryophyta

Bryophyta

Bryophyta

Bryophyta

Bryophyta

Bryophyta

Bryophyta

Bryophyta

Bryophyta

Bryophyta

Bryophyta

Bryophyta

Bryophyta

Bryophyta

Bryophyta

Bryophyta 
Rhodobryum roseum

Rhytidiadelphus loreus

Rhytidiadelphus squarrosus agg.

Rhytidiadelphus triquetrus

Sanionia uncinata

Sciuro-hypnum reflexum

Sciuro-hypnum starkei agg.

Sphagnum centrale

Sphagnum girgensohnii

Sphagnum quinquefarium

Sphagnum russowii

Straminergon stramineum

Tetraphis pellucida

Barbilophozia attenuata

Barbilophozia barbata

Barbilophozia floerkei

Barbilophozia hatcheri

Barbilophozia lycopodioides

Blepharostoma trichophyllum

Calypogeia azurea

Calypogeia integristipula

Calypogeia muelleriana

Calypogeia neesiana

Cephalozia bicuspidata

Cephalozia lunulifolia

Cephaloziella sp.

Chiloscyphus polyanthos

Diplophyllum albicans

Diplophyllum taxifolium

Lepidozia reptans

Lophocolea bidentata

Lophocolea heterophylla

Lophozia longidens

Lophozia obtusa

Lophozia ventricosa agg.

Mylia taylorii

Plagiochila asplenioides

Plagiochila porelloides

Ptilidium ciliare

Ptilidium pulcherrimum

Scapania nemorea

Scapania scandica

Tritomaria quinquedentata

Huperzia selago

Lycopodium annotinum

Athyrium filix-femina

Blechnum spicant

Dryopteris expansa agg.

Dryopteris filix-mas
Bryophyta

Bryophyta

Bryophyta

Bryophyta

Bryophyta

Bryophyta

Bryophyta

Bryophyta

Bryophyta

Bryophyta

Bryophyta

Bryophyta

Bryophyta

Marchantiophyta

Marchantiophyta

Marchantiophyta

Marchantiophyta

Marchantiophyta

Marchantiophyta

Marchantiophyta

Marchantiophyta

Marchantiophyta

Marchantiophyta

Marchantiophyta

Marchantiophyta

Marchantiophyta

Marchantiophyta

Marchantiophyta

Marchantiophyta

Marchantiophyta

Marchantiophyta

Marchantiophyta

Marchantiophyta

Marchantiophyta

Marchantiophyta

Marchantiophyta

Marchantiophyta

Marchantiophyta

Marchantiophyta

Marchantiophyta

Marchantiophyta

Marchantiophyta

Marchantiophyta

Lycopodiophyta

Lycopodiophyta

Pteridophyta

Pteridophyta

Pteridophyta

Pteridophyta 
Gymnocarpium dryopteris

Phegopteris connectilis

Pteridium aquilinum

Picea abies

Pinus sylvestris

Acer platanoides

Agrostis capillaris

Anemone nemorosa

Avenella flexousa

Betula sp.

Calamagrostis phragmitoides

Calluna vulgaris

Carex digitata

Carex pallescens

Chamaepericlymenum suecicum

Convallaria majalis

Crepis paludosa

Dactylorhiza fuchsii

Festuca altissima

Geranium sylvaticum

Hepatica nobilis

Hieracium spp.

Lathyrus linifolius

Lathyrus vernus

Linnaea borealis

Luzula pilosa

Maianthemum bifolium

Melampyrum pratense

Melampyrum sylvaticum

Melica nutans

Milium effusum

Molinia caerulea

Orthilia secunda

Oxalis acetosella

Paris quadrifolia

Polygonatum verticillatum

Populus tremula

Potentilla erecta

Pyrola minor

Rubus saxatilis

Solidago virgaurea

Sorbus aucuparia

Trientalis europaea

Vaccinium myrtillus

Vaccinium vitis-idaea

Valeriana sambucifolia

Veronica officinalis

Viburnum opulus

Viola riviniana
Pteridophyta

Pteridophyta

Pteridophyta

Pinophyta

Pinophyta

Magnoliophyta

Magnoliophyta

Magnoliophyta

Magnoliophyta

Magnoliophyta

Magnoliophyta

Magnoliophyta

Magnoliophyta

Magnoliophyta

Magnoliophyta

Magnoliophyta

Magnoliophyta

Magnoliophyta

Magnoliophyta

Magnoliophyta

Magnoliophyta

Magnoliophyta

Magnoliophyta

Magnoliophyta

Magnoliophyta

Magnoliophyta

Magnoliophyta

Magnoliophyta

Magnoliophyta

Magnoliophyta

Magnoliophyta

Magnoliophyta

Magnoliophyta

Magnoliophyta

Magnoliophyta

Magnoliophyta

Magnoliophyta

Magnoliophyta

Magnoliophyta

Magnoliophyta

Magnoliophyta

Magnoliophyta

Magnoliophyta

Magnoliophyta

Magnoliophyta

Magnoliophyta

Magnoliophyta

Magnoliophyta

Magnoliophyta 